Linköping Studies in Science and Technology

Dissertation No. 1983

\title{
Theoretical and experimental studies of ternary and quaternary nitrides for machining and thermoelectric materials
}

Robert K.M. Pilemalm
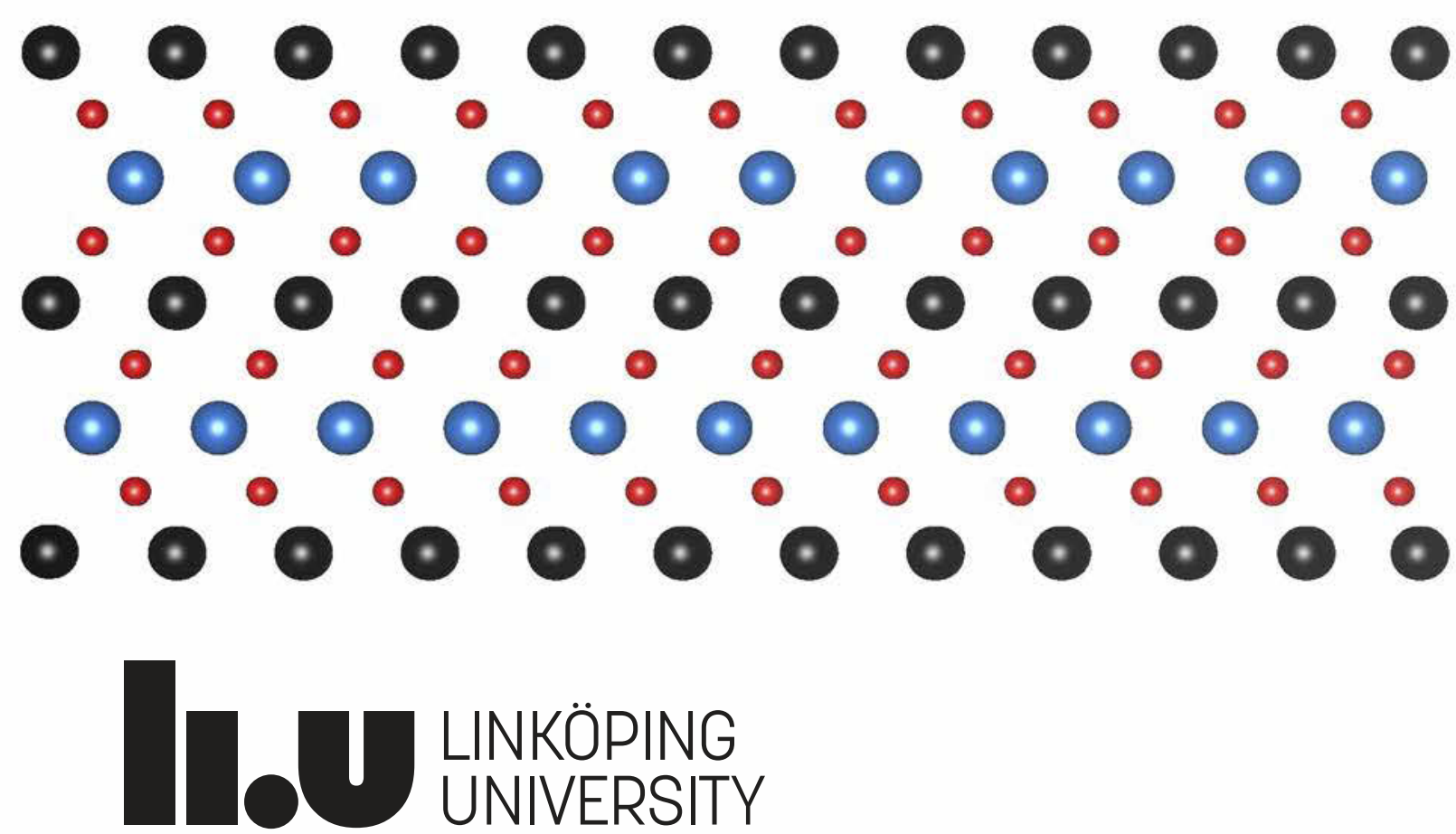


\title{
Theoretical and experimental studies of ternary and quaternary nitrides for machining and thermoelectric materials
}

\author{
Robert K.M. Pilemalm
}

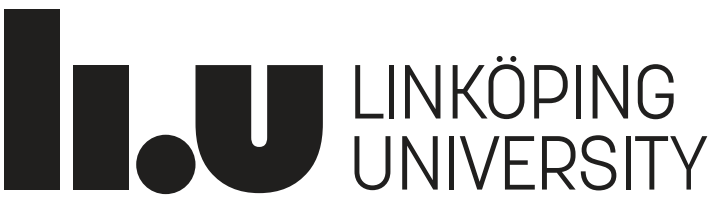

Thin Film Physics Division

Department of Physics, Chemistry, and Biology (IFM)

Linköping University, SE-581 83 Linköping, Sweden 
The cover image illustrates the structure of an inverse MAX phase.

(C) Robert K.M. Pilemalm

ISBN 978-91-7685-114-2

ISSN 0345-7524

Typeset using $\mathrm{LT}_{\mathrm{E}} \mathrm{X}$

Printed by LiU-Tryck 2019

URL: http://urn.kb.se/resolve?urn=urn:nbn:se:liu:diva-155101 
A fight against brain tumor 



\section{Abstract}

Nitrides are used as coatings and thin films for a wide range of applications. The study and use of nitrides in the recent decades have shifted towards ternary, quaternary or even higher order (complex) nitrides. There is an interest to use ternary and quaternary nitrides for machining and thermoelectric materials, because it gives the possibility to choose composition and thereby design the materials properties. This thesis presents research results on TiAlN and and TiAlN-based coatings that are used as hard coatings for machining and on ternary scandium nitrides that are of interest for thin films for thermoelectric applications.

The high-pressure high-temperature behavior of cubic TiAlN deposited on cubic boron nitride has been experimentally studied. It has been shown that the spinodal decomposition, which means decomposition into cubic domains enriched in TiN and AlN, is delayed as a result of high pressure compared to ambient pressure. No chemical interaction between coating and substrate occurs. TiZrAlN has been theoretically and experimentally studied at high temperature. The results show that the when $\mathrm{Zr}$-content is decreased and the Al-content is increased the decomposition route changes from nucleation and growth to spinodal decomposition. The microstructure evolution with temperature depends on the initial composition. In the case where the decompositon starts with only spinodal decomposition the microstructure at $1100{ }^{\circ} \mathrm{C}$ consists of domains that are larger than in the case where the decomposition occurs by nucleation and growth.

$\mathrm{ScMN}_{2}(\mathrm{M}=\mathrm{V}, \mathrm{Nb}$, Ta) phases have been experimentally demonstrated for $\mathrm{M}=\mathrm{Nb}$ and $\mathrm{Ta}$ in a few studies, but have not been much investigated. In this theseis, their crystal structure, stability, elastic properties, electronic structure and thermoelectric properties have been studied. At $0 \mathrm{~K}$ and $0 \mathrm{GPa}$ it has been shown that these three phases are thermodynamically and elastically stable. Additionally, these are narrow-bandgap semiconductors and their thermoelectric properties can be tuned by doping. Pressure has a stabilizing effect on these structures. When pressure increases from 0-150 GPa the elastic constants and moduli increases in the range $53-317 \%$. 


\section{Populärvetenskaplig sammanfattning}

Det postindustriella samhälle som nu upplevs kännetecknas bland annat av utveckling av alltmer högteknologiska produkter. En förutsättning för framtagandet av exempelvis datorer, smartmobiler, bränsleceller, solceller och kommunikationssatelliter är utveckling och design av material med lämpliga egenskaper. Idag utgör design och framställandet av nya material till mångt och mycket en del av nanoteknologin genom att materialdesignen i många fall görs på nano- eller rentav atomnivå. Beläggningar och skikt får alltmer betydelse inom materialutvecklingen, vilket innebär att ett strukturmaterial med för en tillämpning viktiga egenskaper beläggs med ett tunnt lager av ett annat material. Genom att göra det går det att modifiera och anpassa materialegenskaperna hos den färdiga produkten. Då dessa skikt är tunnare än en mikrometer benämns de tunna filmer och det är vidare faktiskt möjligt att syntetisera tunna filmer som enbart består av ett atomlager.

Nitrider eller med andra ord kvävebaserade kemiska föreningar används till beläggningar och tunna filmer. Ett område där keramiska nitrider används är inom skärande bearbetning. Skärverktygen för detta ändamål utsätts under bearbetningsprocessen för högt tryck och hög temperatur och en viktig egenskap hos materialen är att de är hårda eller till och med härdas under processen. På så sätt kan livslängden hos skärverktygen och därmed produktiviteten öka. I den här avhandlingen presenteras forskningresultat kring en nitridbeläggning bestående förutom kväve av grundämnena titan och aluminium samt en annan legerad nitridbeläggning bestående av grundämnena titan, alumunium och zirkonium.

Fortsättningsvis används nitrider som tunna filmer för att omvandla skillnader i temperatur mellan olika delar av ett material till elektrisk ström, vilket är att utnyttja en effekt som benämns den termoelektriska effekten. För att dessa beläggningar ska utnyttjas effektivt är det viktigt att så lite värme som möjligt genereras samtidigt som den elektriska effekten maximeras. Inom materialdesign har det blivit alltmer vanligare att datorsimulera ett material innan det framställs, för att kunna förutsäga dess dess egenskapar. Dessa simuleringar utgår ofta från kvantmekanik. En kvantmekanisk teori som används till detta syfte benämns tä- 
thetsfunktionalteori. I den här avhandlingen presenteras forksningsresultat baserade på täthetsfunktionalteori, vilka berör stabilitet samt elastiska, mekaniska och elektroniska egenskaper hos en klass av nitrider. Dessa nitrider har en speciell och inte hittills särskilt utforskad atomstruktur. I den här avhandlingen består materialet alltid av kväve och skandium samt ett tredje grundämne, vilket utgörs av tantal, niob eller vanadin.

I avhandlingen visas det för titanaluminiumnitrid att det sönderfall som vid hög temperatur orsakar det sönderfall som leder till härdning av materialet fördröjs om ett högre tryck läggs till, vilket förklarar varför beläggningen lämpar sig för skärande bearbetning. Om zirkonium läggs till i beläggningen visas det vidare vad som avgör och på vilka olika sätt som den legeringen sönderfaller vid hög temperatur. Detta har ett värde för att legeringen ska kunna utvecklas till att användas till verktyg för skärande bearbetning. För skandiumnitriderna återges i avhandlingen resultaten av beräkningar av deras grundläggande materialegenskaper. De är stabila, utgör halvledare och är inressanta för termoelektriska tillämpningar. 
This thesis is the result of my work as a Ph.D. student at the Department of Physics, Chemistry and Biology (IFM) of Linköping University in Sweden. During my studies it was unfortunely discovered that I since childhood or even birth suffered from a brain tumor (Gangliocytoma). Because of this sick leave the studies are divided into two periods. From January 2011 to November 2014, I worked in the Nanostructured Materials Division and from October 2017 to April 2019 I worked in the Thin Film Physics Division. On 5th June 2015 I woke up after brain surgery and my tumor had been successfully removed. This made me more motivated to focus on finalizing this thesis after the break in the studies.

Furthermore, this thesis is based on and extended from my Licentiate thesis TiAlN-based Coatings at High Pressures and Temperatures (Licentiate thesis No. 1690, Linköping Studies in Science and Technology), that was presented 17th December 2014. My experimental research has been conducted in collaboration with Sandvik, SECO Tools, Element Six, Uddeholms, SKF and Dalarna University in Sweden and has also been performed at Petra III, DESY in Hamburg in Germany. The theoretical calculations were carried out using supercomputer resources provided by the Swedish National Infrastructure for Computing (SNIC) performed at the National Supercomputer Centre (NSC).

The work has been funded by the Swedish Knowledge Foundation (KK-stiftelsen) and by the Swedish Foundation for strategic Research (SSF) both through the program Designed Multicomponent Coatings (Multifilms) and through Per Eklund's Future Research Leaders 5 Grant and finally by the Department of Physics, Chemistry and Biology (IFM) at Linköping University 



\section{Acknowledgements}

First of all, I would like to thank very much my main supervisor Per Eklund and co-supervisor Sergei Simak for valuable guidance and support. I would also like to thank my former main supervisor Magnus Odén and former co-supervisors Rachid M'saoubi and Mikael Olsson. In particular, I would like to thank Lars Hultman, who has helped me throughout my Ph.D. studies. During my studies many other have meant a lot to me in different ways or have somehow supported me and below they are listed.

The people that have supported my research at Sandvik, SECO Tools, Element Six, Uddeholms and SKF:

Lars Johnson, Krister Edlund, Per-Eric Ekholm, Jon Andersson, Mats Johansson Jõesaar, Anna Sjögren, Åke Andersin, Staffan Gunnarsson and Jacek Kaminski.

Current and passed colleagues at IFM:

Bilal Syed, Mattias Severin, Karl-Fredrik Berggren, Iryna Yakymenko, Leif Johansson, Roger Uhrberg, Rikard Forsén, Niklas Norrby, Axel Knutsson, Lina Rogström, Naureen Ghafoor, Björn Alling, Hanna Fager, Phani Kumar Yalamanchili, Amie Fallqvist, Olof Tengstrand, Sit Kerdsongpanya, Susanne Sveen, Per-Olof Holtz, Peter Münger, Mikael Syväjärvi, Hans Lind, Thomas Lingefelt, Therese Dannetun, Magnus Boman, Emma Björk, Igor Abrikosov, Per Persson, Ludvig Landälv, Per Söderlind, David Engberg, Erik Ekström, Lena Martinsson, Joel Davidsson, Weine Olovsson, Jianqiang Zhu, Martin Magnuson and Johan Nyman.

Family and friends:

Lennart Pilemalm, Lena Pilemalm, Corina Pilemalm, Eila Ekström, Sture Johansson, Kerstin Pilemalm Bergenholtz, Monica Bergsten, Örjan Pilemalm, Jan Pilemalm, Gert Pilemalm, Bo Johansson, Margareta Knaller, Agnes Knaller, Anna Stigsdotter, Markus Landberg, Sebastian Thylin, André Gunnarsson, Markus 
Avén, Philip Avén, Gilbert Tekoah, Roland Rossow, Karin Rossow, Alexander Rossow, Isak Rossow, Kristofer Horkeby, Benjamin Ankarhorn, Urban Bergsten, Sofie Pilemalm, Robert Persson, Kurt Alalehto, Andreas Emretsson, Kristian Hagenkrona, Kristian Karlsson, Josef Mellqvist, Embla Holstein, Jemima Ankarhorn, Sophie Påhlsson, Marcus Striednig and Anna Irebring.

Physicians and other health professionals:

Patrick Vigren, Lovisa Tobieson, Kerstin Boberg, Lena Björkman, Michael Jon, Marie Lindgren, Ann-Charlotte Bremer and Elisabeth Skogh.

Other people:

Torbjön Larsson, Janerik Lundquist, Jan Knutsson-Hall and Tomas Hägg.

I find my strength in the motto of the Swedish King Karl IX:

"Fortitudo mea Jehovah"

$\rho$ BERT $\pi$ LeMaLM, a $\in \mathrm{N}$,

April 2019 
$\begin{array}{ll}\text { List of Included Papers } & 1\end{array}$

Contribution to the Included Papers $\quad 3$

1 Introduction $\quad \mathbf{5}$

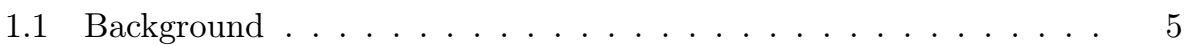

1.2 Thin Films and Coatings . . . . . . . . . . . . . . 5

1.3 Epistemological Approach and Method . . . . . . . . . . . . 6

1.4 Research Goals . . . . . . . . . . . . . . . . . . . 6

2 Materials Science $\quad 9$

2.1 Phases and Phase Transformations . . . . . . . . . . . . . . . 9

2.2 Nucleation and Growth . . . . . . . . . . . . . . . . . . . . . 10

2.3 Spinodal Decomposition . . . . . . . . . . . . . . . . . . . 10

2.4 Hardness and Age Hardening . . . . . . . . . . . . . . . . . . . 12

2.5 Elastic Properties . . . . . . . . . . . . . . . . . . . . 13

2.6 Thermoelectrics . . . . . . . . . . . . . . . . . . . 13

2.7 Thin Film Growth . . . . . . . . . . . . . . . . 14

3 Experimental Techniques $\quad \mathbf{1 5}$

3.1 Reactive Cathodic Arc Deposition . . . . . . . . . . . . . . . 15

3.2 High-pressure High-temperature Experiments . . . . . . . . . . . . 17

4 Characterization Techniques $\quad 19$

4.1 X-ray Diffraction . . . . . . . . . . . . . . . . . . . . . 19

4.2 In Situ Wide-angle X-ray Scattering . . . . . . . . . . . . . . 20

4.3 Transmission Electron Microscopy . . . . . . . . . . . . . . 21

4.4 TEM Sample Preparation . . . . . . . . . . . . . . . . . 24

4.5 Nanoindentation . . . . . . . . . . . . . . . . 25 
5 Theoretical Modeling $\quad 27$

5.1 Density Functional Theory . . . . . . . . . . . . . . . . 27

5.1.1 Theoretical Background . . . . . . . . . . . . . 27

5.1.2 The Hohenberg-Kohn Theorems . . . . . . . . . . . . . 29

5.1.3 The Kohn-Sham Equations . . . . . . . . . . . . . . . . . . 29

5.1.4 Exchange-correlation Effects . . . . . . . . . . . . 31

5.1 .5 Plane Waves . . . . . . . . . . . . . . . . . 31

5.1.6 Pseudopotentials and Projector Augmented Waves . . . . . 32

5.2 Mean Field Approximation . . . . . . . . . . . . . . . . . . . 32

6 Material Systems 33

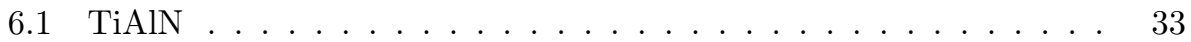

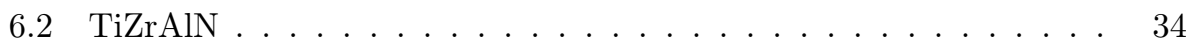

6.3 Tungsten Carbide . . . . . . . . . . . . . . . . . . . . . . . . . . 35

$6.4 \mathrm{PCBN} \ldots \ldots \ldots \ldots \ldots$

6.5 MAX phases ............................ 36

$6.6 \mathrm{ScTaN}_{2}, \mathrm{ScNbN}_{2}$ and $\mathrm{ScVN}_{2} \ldots \ldots . \ldots . \ldots 37$

7 Summary and Contribution to the Field 41

7.1 TiAlN and TiAlN-based Coatings . . . . . . . . . . . . . . . . 41

7.2 Inverse MAX phases . . . . . . . . . . . . . . . . . . . . 42

$\begin{array}{ll}\text { Bibliography } & 45\end{array}$

$\begin{array}{ll}\text { Paper I } & 51\end{array}$

$\begin{array}{ll}\text { Paper II } & 75\end{array}$

$\begin{array}{lr}\text { Paper III } & 87\end{array}$

$\begin{array}{ll}\text { Paper IV } & 99\end{array}$

$\begin{array}{ll}\text { Paper V } & 115\end{array}$

$\begin{array}{ll}\text { Paper VI } & 135\end{array}$ 
[I] High pressure and high temperature behavior of TiAlN coatings deposited on $c$-BN substrates

R. Pilemalm, J. Zhu, A. Sjögren, J.M. Andersson and M. Odén

In manuscript

[II] High temperature phase decomposition in $\operatorname{Ti}_{\mathrm{x}} \mathrm{Zr}_{\mathrm{y}} \mathrm{Al}_{\mathrm{z}} \mathrm{N}$

H. Lind, R. Pilemalm, L. Rogström, F. Tasnádi, N. Ghafoor, R. Forsén, L.J.S. Johnson, M.P. Johansson-Jöesaar, M. Odén and I.A. Abrikosov

AIP Advances, 4, 127147 (2014)

[III] Decomposition routes and strain evolution in arc deposited TiZrAlN coatings

L. Rogström, M.P. Johansson Jõesaar, R. Pilemalm, N. Ghafoor, L.J.S. Johnson, N. Schell and M. Odén

Journal of Alloys and Compounds, 779, 261-269 (2019)

[IV] Thermodynamic stability, thermoelectric, elastic and electronic structure properties of $\mathrm{ScMN}_{2}$-type $(\mathrm{M}=\mathrm{V}, \mathrm{Nb}, \mathrm{Ta})$ phases studied by ab initio calculations

R. Pilemalm, L. Pourovskii, I. Mosyagin, S. Simak and P. Eklund

Condensed Matter, 4(36), 1-14 (2019) 
[V] Effects of high pressure on $\mathrm{ScMN}_{2}$-type $(\mathrm{M}=\mathrm{V}, \mathrm{Nb}, \mathrm{Ta})$ phases studied by density functional theory

R. Pilemalm, S. Simak and P. Eklund

Accepted for publication in Results in Physics

[VI] The effect of point defects on the electronic density of states of $\mathrm{ScMN}_{2}$-type $(\mathrm{M}=\mathrm{V}, \mathrm{Nb}, \mathrm{Ta})$ phases

R. Pilemalm, S. Simak and P. Eklund

Submitted for publication 


\section{Contribution to the Included Papers}

\section{Paper I}

High pressure and high temperature behavior of TiAlN coatings deposited on $c$-BN substrates

The author was responsible of the planning, took part in the deposition, the HPHT experiments and the experimental characterization, discussed the results and wrote the manuscript.

\section{Paper II}

\section{High temperature phase decomposition in $\mathrm{Ti}_{\mathrm{x}} \mathrm{Zr}_{\mathrm{y}} \mathrm{Al}_{\mathrm{z}} \mathrm{N}$}

The author took part in the planning, the deposition and the experimental characterization, discussed the results, wrote parts of the manuscript related to the experiments and commented on all of the manuscript.

\section{Paper III}

Decomposition routes and strain evolution in arc deposited TiZrAIN coatings

The author took part in the planning, the deposition and the in-situ experimental characterization, discussed the results and commented on all of the manuscript. 


\section{Paper IV}

Thermodynamic stability, thermoelectric, elastic and electronic structure properties of $\mathrm{ScMN}_{2}$-type $(\mathrm{M}=\mathrm{V}, \mathrm{Nb}$, Ta) phases studied by ab initio calculations

The author was responsible of the planning, performed all of the calculations except the transport calculations, discussed the results and wrote most of the manuscript.

\section{Paper V}

Effects of high pressure on $\operatorname{ScMN}_{2}$-type $(\mathrm{M}=\mathrm{V}, \mathrm{Nb}, \mathrm{Ta})$ phases studied by density functional theory

The author was responsible of the planning, performed all the calculations, discussed the results and wrote the manuscript.

\section{Paper VI}

The effect of point defects on the electronic density of states of $\mathrm{ScMN}_{2}$ type $(\mathrm{M}=\mathrm{V}, \mathrm{Nb}, \mathrm{Ta})$ phases

The author was responsible of the planning, performed all the calculations, discussed the results and wrote the manuscript. 


\section{CHAPTER 1}

Introduction

\subsection{Background}

Ever since man started to use and design tools, the choice of materials has been a factor to consider. In this sense it can be viewed that materials science or rather materials technology is one of the oldest disciplines, but of course there has been a development in the understanding and design of materials since man once early in history started to make tools out of wood and stone [1]. In our time, a distinction between thin films and bulk materials has been made. Materials science of coatings and thin films has become a well-established line of research. In fact, people encounter coatings and thin films daily in life sometimes without knowing their importance.

The use of thin films has the purpose of tuning or adding properties to an item often consisting of another material that has useful or beneficial properties for a specific application [2]. Thin films and coatings are furthermore used in a variety of applications and the properties that are modified could for instance be decorative, optical, resistive, mechanical or thermal [3]. The science of thin films and coatings is interdisciplinary [4] and involves solid state physics, physical metallurgy, quantum mechanics and thermodynamics. Both theoretical and experimental considerations are needed to understand their electronic structure together with their microstructural evolution and how this in turn relates to the properties of the thin film.

\subsection{Thin Films and Coatings}

Thin films have a thickness in the range nanometers to micrometers, while the term "coatings" is conventionally used for layers of several micrometers or more. 
Thin films are deposited on bulk materials (substrates), which implies that the properties of bulk materials can be combined with the properties of a specific thin film. In order to produce a thin film or a coating chemical vapor deposition (CVD) or physical vapor deposition (PVD) are widely used [5].

The CVD technique takes advantage of chemical reactions between molecules, referred to as precursors that contain the atoms that finally are to compose the structure of the thin film. The gaseous precursors are carried into a reactor with a carrier gas where the chemical reactions take place [6]. One way of controlling the process is by increasing the temperature to faciliate chemical reactions [5]. One advantage of CVD is that complex geometries can be deposited [7].

$\mathrm{PVD}$, on the other hand, is based on physical processes with many different kinds of PVD techniques available. All coatings in this thesis are deposited by the PVD technique cathodic arc deposition [8, 9]. Also, the related technique magnetron sputtering is important.

For magnetron sputtering, an ionized sputtering gas is used in order to bombard the solid target material in a way controlled by the magnetrons. [10, 11]. That results in a controlled removal of target-atoms (ions and electrons). When these sputtered species reach the substrate a film may form. In the case of nitrides the film growth most often takes place in the presence of $\mathrm{N}_{2}$

\subsection{Epistemological Approach and Method}

Even though materials science is interdisciplinary, it comprises its own paradigm, a concept originally described by the philosopher Thomas Kuhn in his work The Structure of Scientific Revolutions [12]. The current paradigm is illustrated in Figure 1.1. There are four bases in this way of representing the paradigm: structure and composition, properties, synthesis and modeling. The bases are all interconnected with each other.

During the scientific processes of this thesis, deductive reasoning [13] was used to reach logical conclusions. In physics Popper's concept of falsifiability is a fundamental notion, when new theories are developed $[14,15]$. This means that there is a capacity for some proposition, statement, theory or hypothesis to be proven wrong. In this thesis, theoretical predictions on material properties deduced from fundamental theories and even new hypothetical materials are proposed, but even though these predictions are deduced from theories that are falsifiable, the material properties also needs to be verified by measurements. It can also be noted that the experimental methods are based on applications of theories that are falsiable. For instance, if a distance between atoms in a crystal are theoretically predicted and if an experimental method confirms this prediction, this distance is regarded as scientifically correct.

\subsection{Research Goals}

The aim of this thesis is to increase the fundamental understanding of ternary and quaternary nitrides for coatings and thin films from a materials scientific point of 


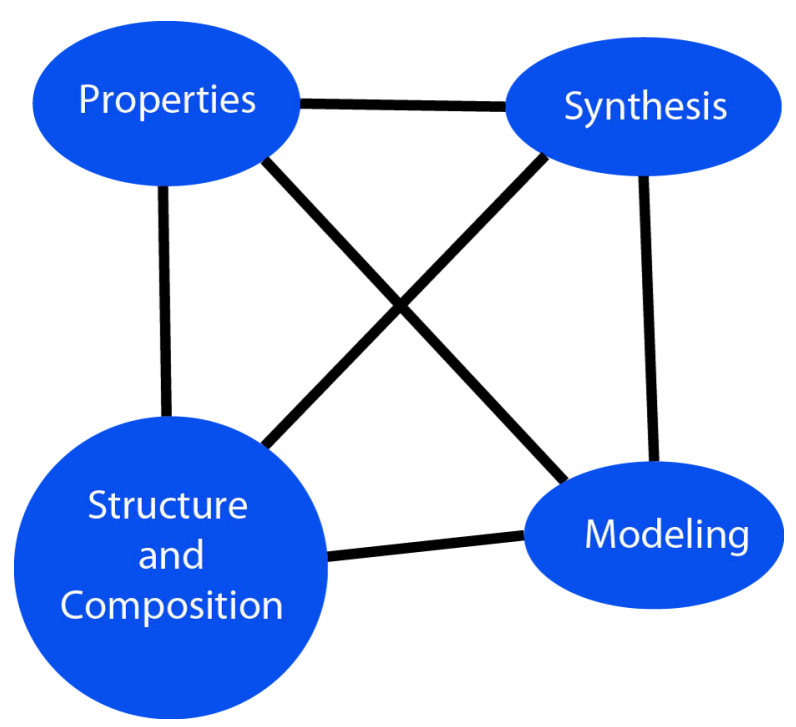

Figure 1.1. The paradigm of materials science.

view. This includes material properties and structure during different temperature and pressure conditions. From thermodynamics it is important to study the phase stability and possible decomposition of all nitrides, but also by alloying choosing appropriate candidates to applications. The coatings are in interest to applications especially for machining and thermoelectric applications and thereby there is an aspect of development of coatings or thin films included as well. 


\section{CHAPTER 2}

Materials Science

\subsection{Phases and Phase Transformations}

This work is basically about crystalline solids, i.e., the studied materials have an ordered repeated structure even though it can consist of many millions of atoms. The repeated structure is referred to as a lattice. Because lattices are ordered, a unit cell that builds up the lattice can be distinguished [16]. The positions of the atoms in the unit cell is in the 3-dimensional case linear combinations of three basis vectors. For this thesis the most important unit cells are faced centered cubic (fcc) and hexagonal close packed (hcp). The term phase is defined as a homogenous portion of a system that has uniform physical and chemical properties. For instance in the case of water ice (solid), liquid and vapor are three different phases. For a solid material, the term "phase" refers to a homogeneous portion of a system with the same composition and crystal structure. [17].

However, the phase of a material is not static. Phase transformations can occur due to changes in for instance temperature and pressure. Additionally, the phase of a material often depends on its composition. In doing experiments, one or more factors are often set constant and one or others are varied [18]. For this work, temperature usually is the controlling factor and for Paper I also time is considered. A phase transformation is governed by the thermodynamics and kinetics of the situation. A phase transformation can occur through different processes, that are described in the following two sections.

Stability of a phase is an important concept. In phase diagrams, the phase of each condition always refers to a stable phase. Material systems in nature tend to be stable and if an unstable phase would appear, nature would aim to transform it to the corresponding stable phase. Thermodynamically, this is described with the help of the free energy of the material system and the striving for stability is 
then expressed as minimization of the free energy.

The Gibbs free energy, $G$, is used for a material system and with the enthalpy, $H$, the temperature, $T$, and the entropy, $S$, of the system it is expressed [19]:

$$
G=H-T S
$$

The minimization of energy gives then the condition for equilibrium as:

$$
d G=0
$$

The equilibrium condition is also fulfilled for local minima and in this case the phase is referred as a metastable phase.

\subsection{Nucleation and Growth}

Another phase can be formed by the formation and growth of nuclei, because the increase of size of a nucleus decreases the free energy. However, the formation itself of the nucleus increases the free energy. Only when the nucleus has reached the critical radius, further growth leads to decrease in free energy [20]. Thus, there is an activation energy barrier that has to be overcome first. When the nucleation starts at a grain boundary or an impurity, it is considered as heterogeneous nucleation [21]. The growth needs addition of atoms from the surroundings and thus diffusion must take place which occurs downhill of a concentration gradient [22].

\subsection{Spinodal Decomposition}

It is sometimes possible to obtain alloys i.e. solid solutions consisting of two or more constituents that are immiscible [23]. In a phase diagram the region where these are immiscible is referred to a miscibility gap. A material system is then characterized by not being resistant to infinitesimal changes that for instance could be a fluctuation of composition [24]. This means that there is no barrier to nucleation except barriers for diffusion. In contrast to nucleation and growth uphill diffusion takes place, i.e. diffusion of an element A occurs towards regions with higher A-concentration [25]. Subsequently, if there is a region enriched of one element this region will become even more enriched of the same element due to the spinodal decomposition [26].

The condition of spinodal decomposition can be described thermodynamically with the Gibbs free energy of mixing. For illustration purposes, an alloy between two constituents is used here. In order to compare the solid solution between these and the two separate phases, the Gibbs free energy of mixing, $\Delta G_{m i x}$, is taken into consideration. $\Delta G_{m i x}$ is the difference between Gibbs free energy of the multicomponent alloy and the free energy of the state, where the constituents coexist. These phases are not necessarily stable, but could be metastable. Often this is expressed as a function of a composition variable i.e. the mole or atomic fraction of one of the constituents [26]. In this case this is denoted $x_{A}$. The $\Delta G_{m i x}$ is in general a measure of the stability of a system or the tendency for 


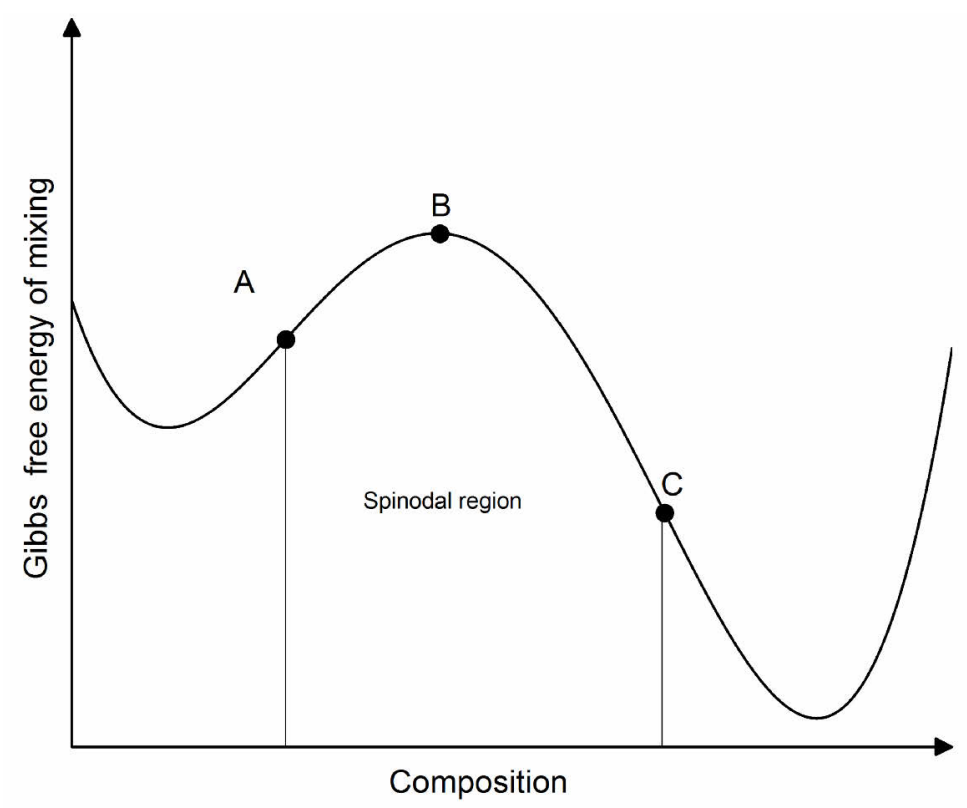

Figure 2.1. Gibbs free energy of mixing for a binary system with a spinodal region.

decomposition and in this context it is a measure of the driving force for spinodal decomposition.

Figure 2.1 shows the Gibbs free energy of mixing as a function of composition. At point $\mathrm{B}$, there is a maximum and a fluctuation of composition will always lead to a decrease in the total free energy and thus this point is unstable. However, the system is not only unstable at $\mathrm{B}$, but also at all points between $\mathrm{A}$ and $\mathrm{C}$, and this is the spinodal region. The reason is that the second derivative with respect to composition is smaller than zero, $\frac{\partial^{2} \Delta G_{m i x}}{\partial x_{A}^{2}}<0$, that has the implication that any small fluctuation will lead to a decrease in the overall energy. The opposite condition, $\frac{\partial^{2} \Delta G_{m i x}}{\partial x_{A}^{2}}>0$, will lead to separation by the nucleation and growth mechanism. [27]

At an early stage, the precipitates are coherent, with no lattice mismatch between them, even though there would have been a lattice mismatch if these were compared in their pure states. The maintenance of the coherency implies lattice strains that in fact affects the movement of dislocations. This in turn affects the hardness of the material [28]. If relaxation occurs after the spinodal decomposition, it implies increased lattice mismatch that also affects the hardness and thus there is an evolution of the hardness when transforming from initial solid solution to the precipitatives. 


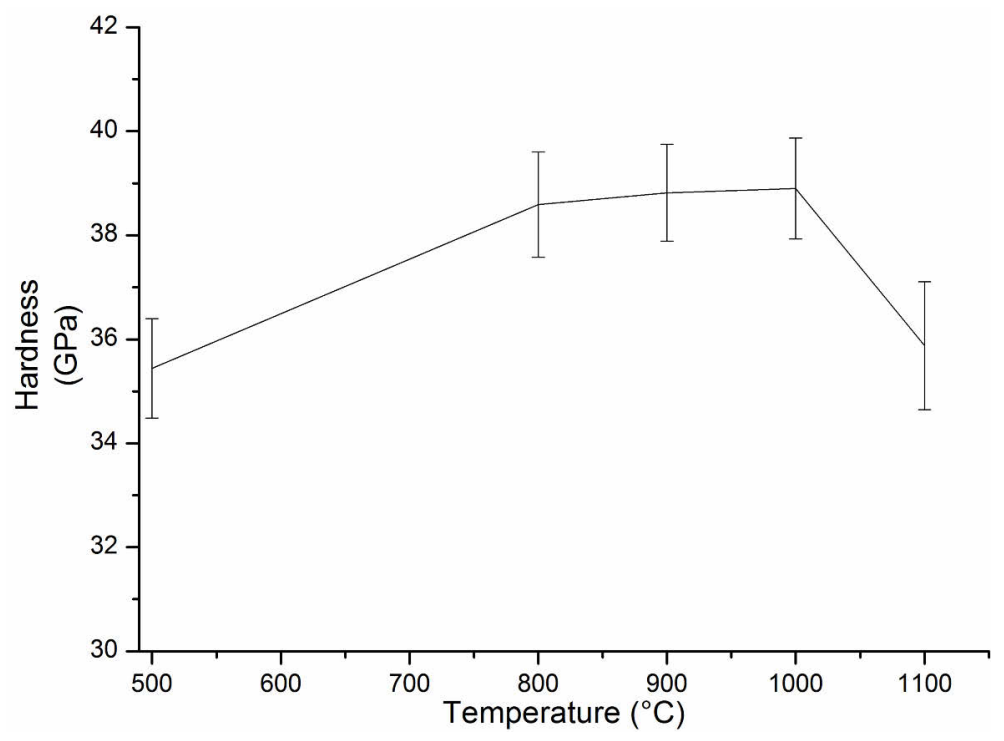

Figure 2.2. Age hardening of $T i_{0.44} Z r_{0.17} A l_{0.40} N$ (Prestudy to Paper II and III).

\subsection{Hardness and Age Hardening}

The most important mechanical property of thin films deposited on materials for machining is hardness. Machining processes using cutting inserts coated with TiAlN can reach temperatures in excess of $1000{ }^{\circ} \mathrm{C}[29,30]$. Thus, not only hardness in the as-deposited state is of interest, but also changes of hardness with temperature and time. Hardness in this context means the ability to resist plastic deformation. One factor causing drop of hardness is movement of dislocations and one of the effects of such movements could be slipping, which in turn is a deformation. Consequently, design of hard composite materials aims to hinder this kind of motion. One way of achieving that is to introduce coherency strains in the thin film materials. That implies an increase in energy needed for a dislocation moving between two material domains [31].

$$
c-\operatorname{TiZrAlN} \underset{1}{\Rightarrow} c-\operatorname{TiZrN}+c-A l N \underset{2}{\Rightarrow} c-\operatorname{TiZrN}+h-A l N
$$

Age hardening is a phenomenon that implies a higher hardness as precipitates of a solid solution cause obstacles for dislocation motion [32, 33]. If the formation is associated with an increase of temperature, this could be beneficial for machining. In studies preceding Paper II and III age hardening was observed for cubic $T i_{0.44} Z r_{0.17} A l_{0.40} N$ that was correlated with the decomposition in Equation 2.3. Figure 2.2 shows the evolution of hardness with temperature of this specific composition and it also illustrates age hardening. The increase of hardness after annealing at $1000{ }^{\circ} \mathrm{C}$ is related to spinodal decomposition in step 1 of the 
mentioned equation and it was also shown that the precipitates were coherent. Furthermore, the drop at $1100{ }^{\circ} \mathrm{C}$ is related to the second step in the equation, when cubic AlN transforms to hexagonal AlN.

\subsection{Elastic Properties}

In this thesis, the standard Voigt notation is used to describe elastic properties. Linear elasticity of a crystal is described as a relationship between the stress tensor component, $\sigma_{i}$, the elastic constant tensor components, $C_{i j}$, and the strain tensor components, $\epsilon_{j}$, which is a generalization of Hooke's law. [34] It is expressed:

$$
\sigma_{i}=\sum_{j} C_{i j} \epsilon_{j}
$$

The $C_{i j}$ tensor have depending on its crystal stucture zero values of some of its components. In this thesis, the study on elastic propertis have focused on hexagonal crystal systems. Then, the $C_{i j}$ tensor takes the form [35]:

$$
C_{i j}=\left(\begin{array}{cccccc}
C_{11} & C_{12} & C_{13} & 0 & 0 & 0 \\
C_{12} & C_{11} & C_{13} & 0 & 0 & 0 \\
C_{13} & C_{13} & C_{33} & 0 & 0 & 0 \\
0 & 0 & 0 & C_{44} & 0 & 0 \\
0 & 0 & 0 & 0 & C_{44} & 0 \\
0 & 0 & 0 & 0 & 0 & C_{66}
\end{array}\right)
$$

In addition, $C_{66}$ is related to $C_{11}$ and $C_{12}$ through [35]:

$$
C_{66}=\frac{\left(C_{11}-C_{12}\right)}{2}
$$

Thus, for a hexagonal lattice it is enough to determine only five elastic constants to obtain a full description of its elastic behaviour. In order to determine the $C_{i j}$ :s these can be done both experimentally by measurement and by performing calculations on the crystal. Concerning calculating them, there are two different main approaches, of which the first one is to introduce distortions in the lattice and to see how these change the energy of the system, that in turn depends on the lattice constants. The other approach is to introduce distortions and then to determine the stresses. By doing that stress-strain curves that are described with Equation 2.4 can be obtained, from which the elastic constants can be extracted. [36].

\subsection{Thermoelectrics}

Materials that are referred as thermoelectric materials have the ability to generate an electric current, when there is a temperature gradient across the material. The difference in temperature causes a net diffusion of of charge carriers from the hot 
part of the material to the cold part. $[37,38]$ To describe this phenomenom the Seebeck coefficient, $S$ is used. It is defined:

$$
S=\frac{\Delta V}{\Delta T}
$$

$\Delta V$ is the difference in voltage between two points in the material and $\Delta T$ is the difference in temperature between the same points. In order to evaluate the efficiency of a thermoelectric material the dimensionless figure of merit, $Z T$, is used. At a temperature, $T, Z$ is defined:

$$
Z=S^{2} \frac{\sigma}{\kappa}
$$

$\sigma$ is the electrical conductivity and $\kappa$ is the thermal conductivity, which has one contribution from electrons and another one from phonons. A good thermoelectric material has $Z T \approx 1$. For efficient materials, the electrical conductivity is high while the thermal conductivity is low. The figure of merit can be changed by doping, but because $S, \sigma$ and $\kappa$ are correlated it is not always easy to improve the figure of merit. The effect of doping is an increase in the number of charge carriers in a material. [38, 39]

\subsection{Thin Film Growth}

Thin film growth includes many different processes, mechanisms and phenomena. Some of the most important for polycrystalline film growth are nucleation, crystal growth and coalescence [40]. Film growth is a complex process and the mentioned phenomena do not only occur sequentially, but are part of many of the film growth stages. The outcome is finally a continuous film. [41]

Primary nucleation means that adatoms, i.e., atoms that have stuck to the substrate surface, form clusters (nuclei) [20]. For a nucleus to form, it needs to reach a critical nucleus size. If this size is not reached, the cluster is not stable and does not survive [42]. Nucleation occurs not only in the first stage of film growth and therefore there also are concepts as repeated and secondary nucleation [43].

Crystal growth or island growth is when individual dispersed crystals grow from many nuclei, but when this occurs the final orientation is not always determined. This can later be changed, when it grows as part of a polycrystalline structure and there is for the collective behavior of the polycrystalline film a dependence of for instance grain size and surface conditions [41, 44].

Coalescence is when larger islands grow at the expense of smaller ones, which happens when two islands come in contact with each other. The interfusion of the islands lead to a reorganization and the new island will become one single crystal. There are different mechanisms for coalescence, but the driving force is always to reduce overall surface energy or interface energy. [43, 45] 
CHAPTER 3

Experimental Techniques

\subsection{Reactive Cathodic Arc Deposition}

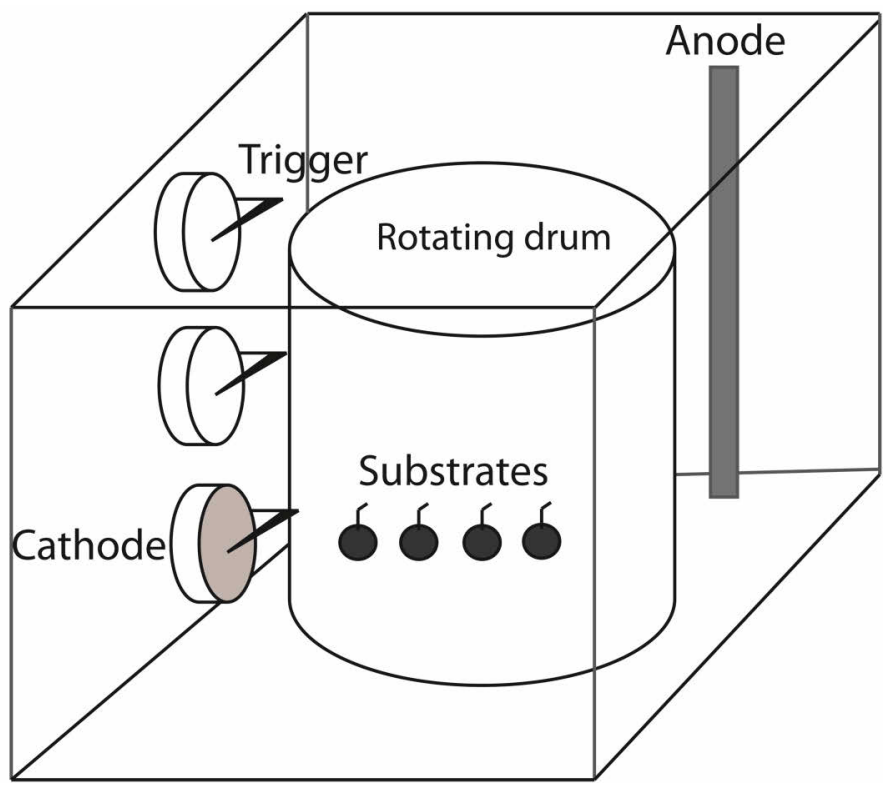

Figure 3.1. Schematic of a deposition chamber 
Cathodic arc deposition is based on the formation of an arc discharge between a cathode and an anode. The cathode consists of the elements of the thin film or the coating that is to be synthesized. For the deposition systems used for synthesis of the coatings of this thesis, a mechanical trigger acting as an anode is in contact with the cathode a short time. When these are separated, a discharge is formed $[46,47]$. The effect of the arc is that electrons, atoms and ions are ejected from a locally heated spot. Due to the electric field in the arc the emitted electrons are accelerated. When they collide with the ejected atoms, ionization occurs. The net result is plasma with a high degree of ionization [47, 48]. Generally, the substrates are negatively biased in order to attract positive ions to the surface of the substrates. When ions reach the substrate, condensation occurs and this leads to nucleation and growth of a film $[47,49]$. It is also possible to lead a reactive gas into the deposition chamber, causing reaction with the ions [50]. In the context of this thesis, this gas was $\mathrm{N}_{2}$, which was the source of nitrogen to the studied nitride films.

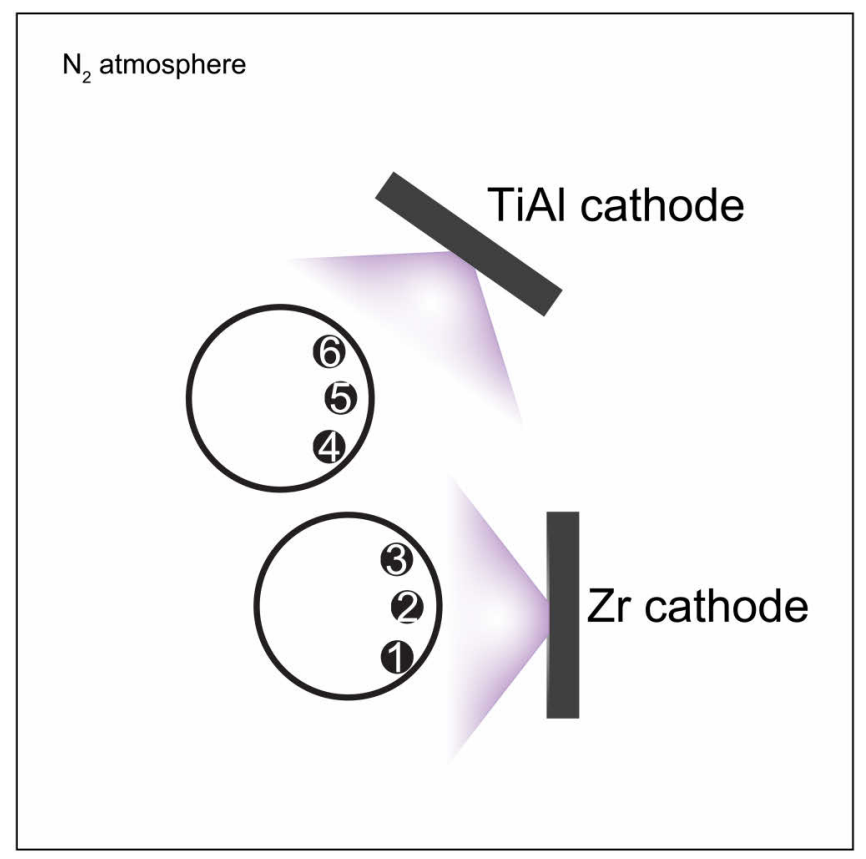

Figure 3.2. Setup inside a deposition chamber

For this work, two different commercial deposition systems were used, but the principles behind the processes are the same. For Paper I, a system that is illustrated in Figure 3.1 was used. Here, a TiAl cathode was used. The specially designed $c$-BN substrates were mounted in rows with clamps on a rotating drum at the same height as the center of the used cathode with the consequence of giving the coatings the same compositions. During deposition the drum was rotating with 
$3 \mathrm{rpm}$. For Paper II, a system with two cathodes mounted on the same height was used, where one cathode consisted of pure $\mathrm{Zr}$ and the other was a TiAl cathode. In this case, WC-Co substrates were mounted in columns on a fixture with each column having different distances from both cathodes as illustrated in Figure 3.2. The idea was to get a composition gradient with different composition in every row. In this case the drum was stationary (no rotation) to ensure homogenous coatings.

\subsection{High-pressure High-temperature Experiments}

The high-pressure high-temperature (HPHT) experiments were performed with a Hall belt apparatus at Element Six in Robertsfors, Sweden. The belt press was first invented to produce synthetic diamond [51] and was also the first system making that commercially possible. Pressure is created mechanically and temperature is controlled by resistive heating. The system has the capability to create and maintain pressures up to $10 \mathrm{GPa}$ and temperatures up to $2000{ }^{\circ} \mathrm{C}$ during the time of several hours $[52,53]$. Figure 3.3 shows, in a simplified way how one part of the system is constructed and with the arms this part is moved into another part of the press, where loads are created hydraulically, [53]. The pressure in the tube is created mechanically by applying forces on the dies. From the anvils the forces are transmitted to the tube that contains the samples and the material of the tube acts as the resistance of the heating.

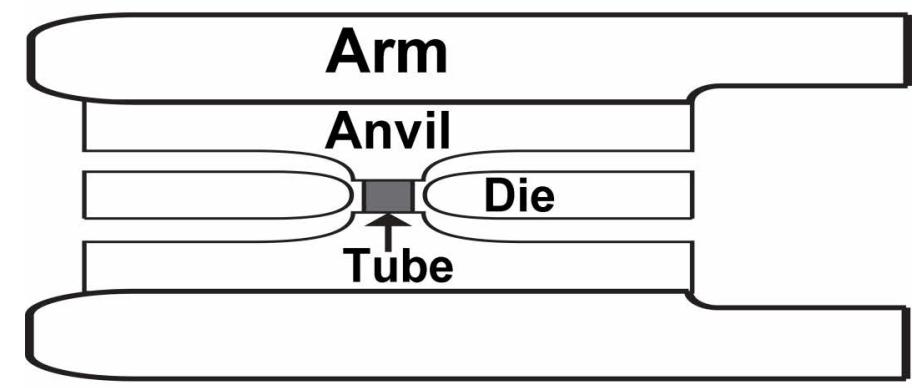

Figure 3.3. A simple illustration of the main part of the Hall belt apparatus

However, the HPHT conditions of the experiments had to be adapted to the attainable conditions. In the experiments, the pressure was set constant to $5.35 \pm$ $0.15 \mathrm{GPa}$, while the holding temperature was either $1050{ }^{\circ} \mathrm{C}$ or $1300{ }^{\circ} \mathrm{C}$ and with a holding time of either 6 minutes or 66 minutes. The tube was mounted in the belt press at room temperature and atmospheric pressure. The heating power was during a first step of 2 minutes ramped to half of the full power and during a second step of 10 minutes ramped to full power followed by a holding step of either 6 or 66 
minutes. The cooling was during a first step of 6 minutes to half of the full power followed by a second step of 11 minutes to zero power. Each material piece was contained in a specially designed capsule illustrated in Figure 3.4. Four capsules were put in the pressure medium that finally was contained in a tube that was specially designed for this experiment. The capsule is first designed to create and maintain pressure and second to give a support in order not to destroy the sample. The separation discs were put in the capsule to make the recovery of the samples after the experiments easier. The inner surface of the capsule that during the experiments was in contact with the coated side of the polycrystalline cubic boron nitride $(\mathrm{PCBN})$ piece was deposited by spraying with a coating consisted of $\mathrm{Al}_{2} \mathrm{O}_{3}$ and $\mathrm{TiO}_{2}$. This was to avoid chemical reactions between the thin film and the Nb-cup that otherwise would have been in contact with the sample. Temperature determination was based on previous measurements on a similar tube with the same design and the same pressure medium and the pressures were determined with the used load and by the dimensions of the parts of the capsule. In order to recover the samples after each experiment the capsule and pressure medium were crushed with a hammer, the ceramic mechanical support by turning and the Nb-cup first by a blasting step followed by the use of pliers and scalpel. For some samples the $\mathrm{Al}_{2} \mathrm{O}_{3}$ and $\mathrm{TiO}_{2}$ coating had sintered on the film surface and this cladding was not possible to remove.

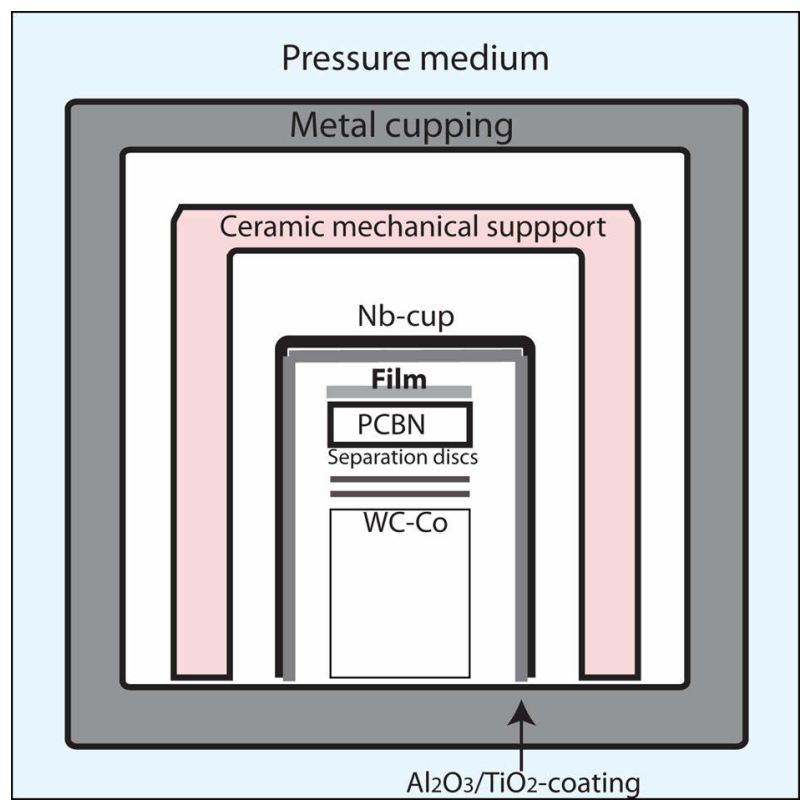

Figure 3.4. Schematic of the construction of the capsule. The white space between parts is only there to make a distinction between the parts. 


\section{CHAPTER 4}

\section{Characterization Techniques}

\subsection{X-ray Diffraction}

X-ray diffraction (XRD) is an analytical technique based on constructive interference between x-rays. The phenomenon of constructive interference was first observed and explained for visible light. However, other kinds of waves can be used and also electrons or neutrons, because they possess wave properties. In the case of a crystal or a lattice, atoms are formed repeatedly and regularly. Atoms are then aligned equidistantly in different planes and furthermore such planes in different directions can be distinguished. [54, 55] In order to get diffraction, the wavelength of the incident beam has to be in the same order as the distance between parallel planes, which are in the order of a few $\AA$. A wavelength of that order belongs precisely to the x-ray spectrum of electromagnetic radiation. If two different beams scatter from two parallel planes and the both scattered beams are still coherent, superposition of the beams will lead to constructive interference or diffraction. This condition can be expressed with Bragg's law [56]:

$$
2 d \sin (\theta)=m \lambda
$$

Here, $d$ is the distance or spacing between two neighbouring parallel planes, $\theta$ the incident angle of the beam and $\lambda$ is the wavelength of the used wave. In Figure 4.1 XRD is schematically illustrated. One advantage of XRD is that it is a nondestructive technique [57].

In ex situ measurements for this thesis, a wavelength of $\lambda=1.540598 \AA$ was used. Furthermore, the Bragg-Brentano technique [55] or $\theta-2 \theta$ geometry was used for XRD measurements. The idea is to vary the incident angle and for each angle measure the intensity. As can be seen in Figure 4.1 the incident angle and the 


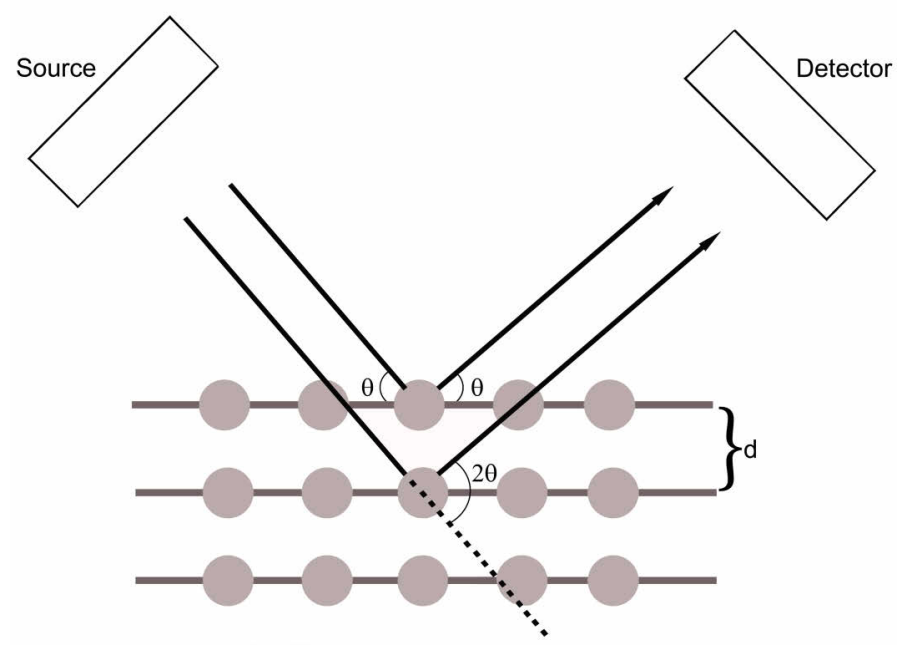

Figure 4.1. Illustration of the Bragg-Brentano geometry for x-ray diffraction.

diffracted angle are the same. In the diffractogram the intensity is plotted as a function of the $2 \theta$ angle. With this setup only grains that have an orientation so that some of their $(\mathrm{hkl})$ planes are parallel to the surface of the sample can be identified in the corresponding diffractogram [58].

\subsection{In Situ Wide-angle X-ray Scattering}

Wide angle $\mathrm{x}$-ray scattering (WAXS) is a technique where scattering between $\mathrm{x}$ ray waves are used [59-61]. The analysis for this work is based on scattering that fulfills Bragg's law in Equation 4.1 and where the x-rays were generated with a synchrotron x-ray source [62]. Electrons are accelerated to a speed close to the speed of light. During the acceleration x-ray radiation will be generated [63]. The x-rays have high energy $(\sim 80 \mathrm{keV})$ or in other words small wavelength and the flux of x-ray photons is high. The advantages are high brilliance, high brightness, that the x-rays are tightly collimated, that samples can be penetrated and that rapid diffraction scans can be performed.

Furthermore, the properties of synchrotron generated x-rays imply that in situ measurements can be performed during high temperature annealing. The setup of this work is schematically illustrated in Figure 4.2. The incoming x-rays stem from one of the beamlines of the used particle accelerator [64] and penetrate the sample that is mounted into a furnace with a graphite heater tube. The tubes on the sides, where x-rays and diffracted x-rays enter and exit the furnace, have glass windows at their outer ends. During annealing the furnace is at vacuum conditions. The distance between sample and detector is relatively small resulting in wide angles, which distinguishes WAXS from small angle x-ray scattering (SAXS) [61]. The 


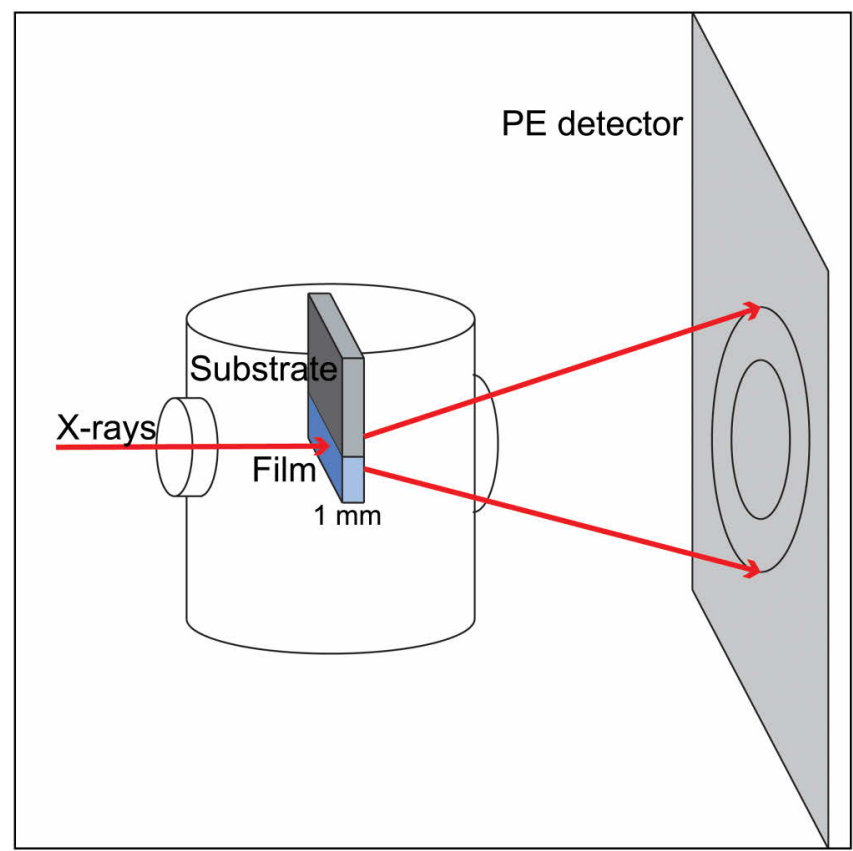

Figure 4.2. The setup for in situ WAXS illustrating the radiation from the beamline, the furnace and the photoelectric detector

diffracted x-ray photons are finally detected by a photoelectric detector.

There is a major difference between the diffractograms obtained with the Bragg-Brentano geometry in Figure 4.1 and the diffraction patterns obtained from the setup in Figure 4.2, which is that the diffraction patterns are 2-dimensional (2D), which means that these consist of rings rather than peaks as in the case of the first setup. It is possible to extract line scans as a function of planar distance, $d$, from the $2 \mathrm{D}$ data. Because the data are $2 \mathrm{D}$ it is possible to obtain line scans in the growth direction and the in-plane direction.

\subsection{Transmission Electron Microscopy}

Before the discovery of the electron Rayleigh's criterion of the resolution of a light-optical microscope (LOM) was formulated according to [65]:

$$
r=0.61 \frac{\lambda}{n \sin (\theta)}
$$

Here, $r$ is the resolution limit, $\lambda$ the wavelength of light, $n$ the refractive index of the medium between the object and the lens. Visible light has approximately a wavelength between 400 and $700 \mathrm{~nm}$. Thus, there is a lower limit of what can be resolved with light. Electrons have de Broglie wavelengths and it is possible to obtain wavelengths smaller than the wavelengths of optical light. Subsequently, 
with the use of beams of electrons instead of photons it is possible to build microscopes with higher resolution than a LOM and it has been shown that Rayleigh's criterion is valid in this context too. In the studies of this thesis an acceleration voltage of $200 \mathrm{keV}$ was used corresponding to a relativistic de Broglie wavelength of $0.025 \AA[66]$.

TEM samples have a thickness less than $100 \mathrm{~nm}$ [67] and the electrons interact with the sample in different ways. These can be transmitted, absorbed, scattered or backscattered, but for TEM the advantage is mainly taken of transmission and scattering. Contrast is caused by differences in diffraction, phase, thickness and mass. By blocking diffracted beams with an aperture in the back focal plane a bright field (BF) image is obtained and this increases the diffraction contrast, because diffracted areas then appear darker [68]. A BF micrograph is shown in Figure 4.3.

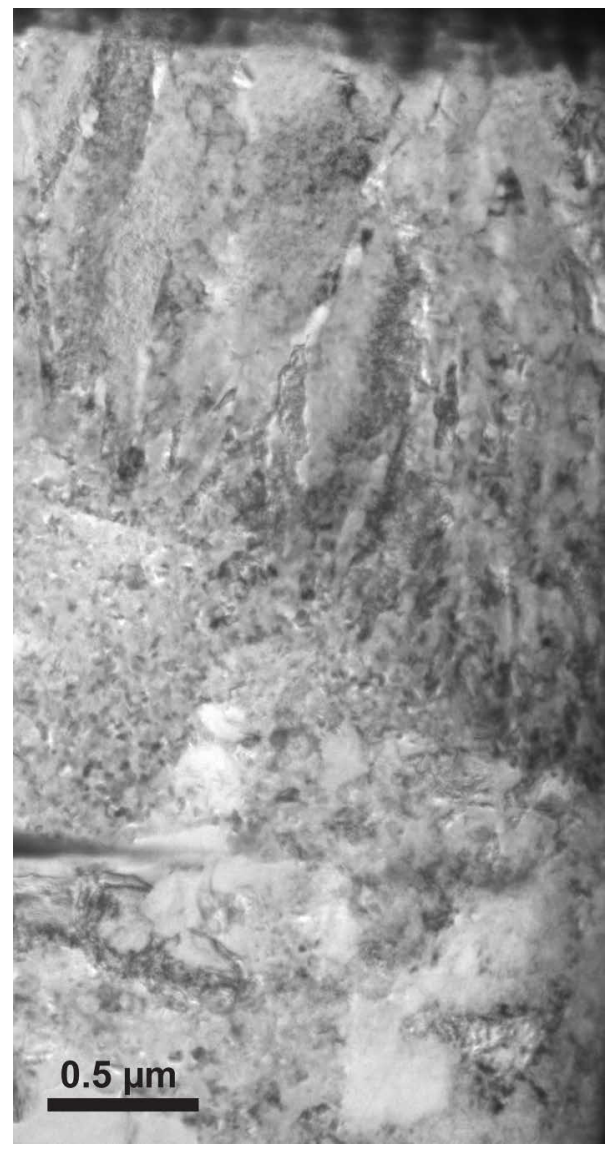

Figure 4.3. A BF micrograph of PCBN deposited with TiAlN. The brightest areas in the bottom are from $c$-BN grains that do not cause much diffraction due to the lower masses of $\mathrm{B}$ and $\mathrm{N}$. 
Bragg's law in Equation 4.1 is always satisfied for diffracted beams in a TEM and in the back focal plane, the diffraction pattern is formed. For this thesis electron diffraction (ED) and in particular selected area electron diffraction (SAED) were used to determine crystal structure.

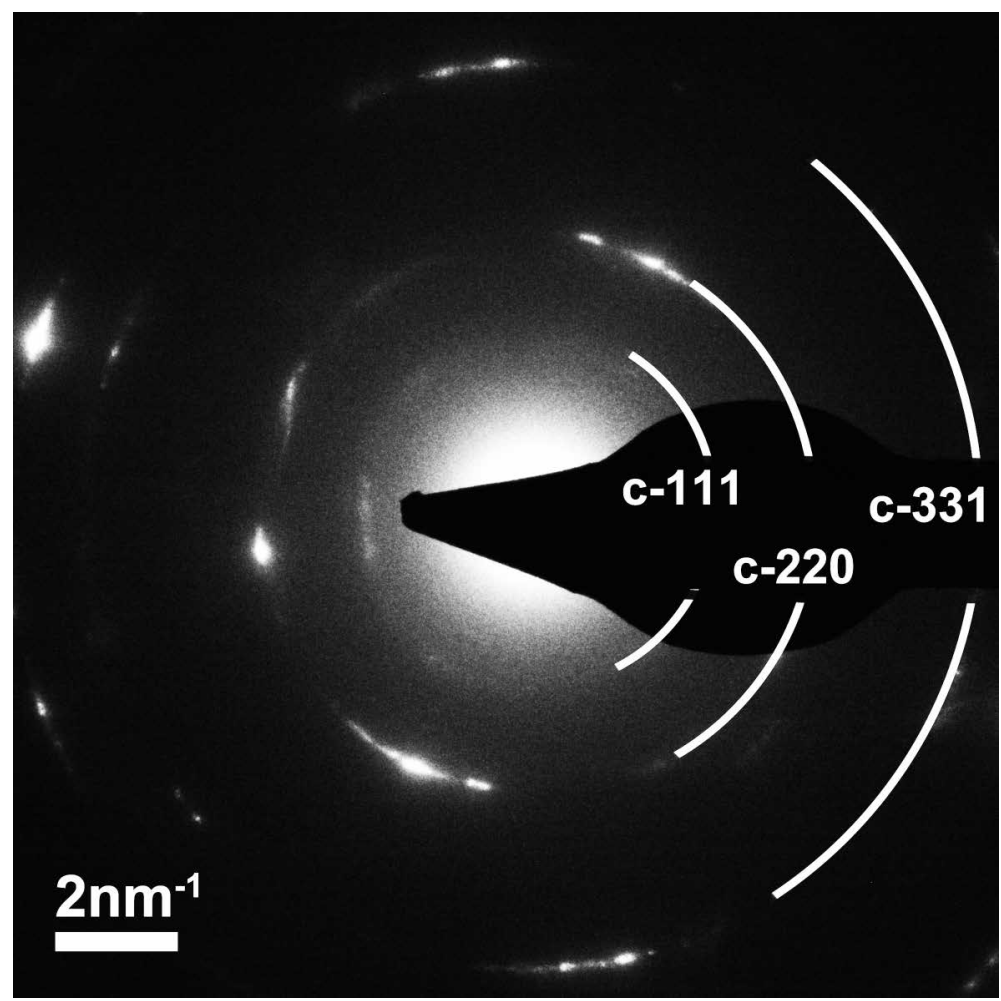

Figure 4.4. An SAED pattern of $c$-TiAlN. In this figure the diffracted planes represented with the rings are indexed.

For SAED, only beams from a specific area for instance from a single grain is selected by blocking beams from all other areas with an aperture and therefore only beams from this selected area are collected in the back focal plane. The diffraction pattern consists either of dots or rings. In Figure 4.4 there is an SAED pattern from an area of $c$-TiAlN coating.

Furthermore, also scanning TEM (STEM) was used for which a nanoprobe is used for scanning all over the specimen $[69,70]$ and when a high angle annular dark field (HAADF) detector [70] is used, mass contrast is significant. When the HAADF detector combined with a high energy dispersive x-ray spectroscopy (EDX) detector are used, an elemental map can be obtained from the detected data. This is because the x-rays emitted when electrons interact with matter are characteristic for each element.

Another used analytical technique related to TEM is electron energy-loss spectroscopy (EELS). For EELS, inelastic scattering between incident electrons and 
atoms are used, which leads to excitation of the atoms with the effect of loss of energy of the incident electrons. The energy-loss is dependent on from which subshell of the element the excitation occurs and the energy-loss is shown in an EELS spectrum [71].

\subsection{TEM Sample Preparation}

A sample used in TEM needs to be electron transparent, that is thinner than $100 \mathrm{~nm}$. For this study two different methods to prepare samples were used and the choice of method depended on the used substrate. For Paper II, conventional sample preparation was used due to the tungsten carbide substrate (WC-Co) while for the harder PCBN substrate in Paper I that was not possible and instead focused ion beam (FIB) was used. The drawback of a FIB sample is that it is in general thicker than a conventionally prepared one.

The FIB instrument uses an ion beam of Ga ions with energies of 5-50 keV in order to do milling of a material piece on microscopic level. This gives the user the possibility to cut in the material and thereby by controlling the beam a crosssection for TEM can be shaped. FIB uses a very fine focusing and the accuracy on nanoscale level is very high, but for this high vacuum is needed [72].

Furthermore, the instrument used here is a combination of a FIB and a SEM. FIB is used to bombard the ions of the thin film and the substrate while SEM is used for imaging. When the ions hit the surface, the material will be sputtered. The user can choose where to bombard the surface with ions and thereby the user works with a controlled machining or milling process.

For the sample preparation a variant of the liftout technique was used [73]. Briefly, this means that an area of interest is first deposited with platinum. The area around is milled or dug to an appropriate depth. After that, a needle is attached to the sample and the sample is lifted out and moved to a copper grid, where sample gets welded followed by thinning with the use of an ion beam until the sample becomes electron transparent. The grid can afterwards easily be mounted in the sample holder of the TEM.

Conventional TEM preparation consists of the steps mechanical polishing and ion milling. First, the sample needs to be cut and fixed in the grid. This was achieved by cutting smaller pieces of the sample so that two pieces with their film sides facing each other together could fit to the grid followed by baking with graphite and araldite. Thereafter, diamond abrasive cloths with different grain sizes were used with $1 \mu \mathrm{m}$ grain size in the final step while the thickness of the sample was around $50 \mu \mathrm{m}$.

The ion milling is achieved by bombardment of Ar-ions with energies in steps typically from $5 \mathrm{keV}$ to less than $1 \mathrm{keV}$. The single sample that is contained in a vacuum chamber is hit with an angle of $5^{\circ}$. The milling ought to be stopped when electron transparency is reached, i.e., a thin region less than $100 \mathrm{~nm}$ thick. 


\subsection{Nanoindentation}

In order the measure hardness nanoindentation was used and the main idea is to continuously load the sample with a tip and at the same time register the changes of indentation depth [74]. When the load for causing plastic deformation, $F_{\max }$, is known and the contact area is given, the hardness, $H^{1}$ is given by [75]:

$$
H=\frac{F_{\max }}{A}
$$

The indents are too small to have their sizes accurately estimated by an optical microscope. Instead the contact area is calculated with the knowledge of the shape of the tip together with the recorded contact depth [75]. For this thesis a diamond Berkovich tip with a pyramidal shape was used. The contact area of the particular used tip as a function of indentation depth was obtained with indentations in fused silica for which the material properties was already known. Figure 4.5 shows a typical load-displacement curve, that is obtained during the nanoindentation, when the tip is loaded and unloaded. From the curve the contact depth can be extracted.

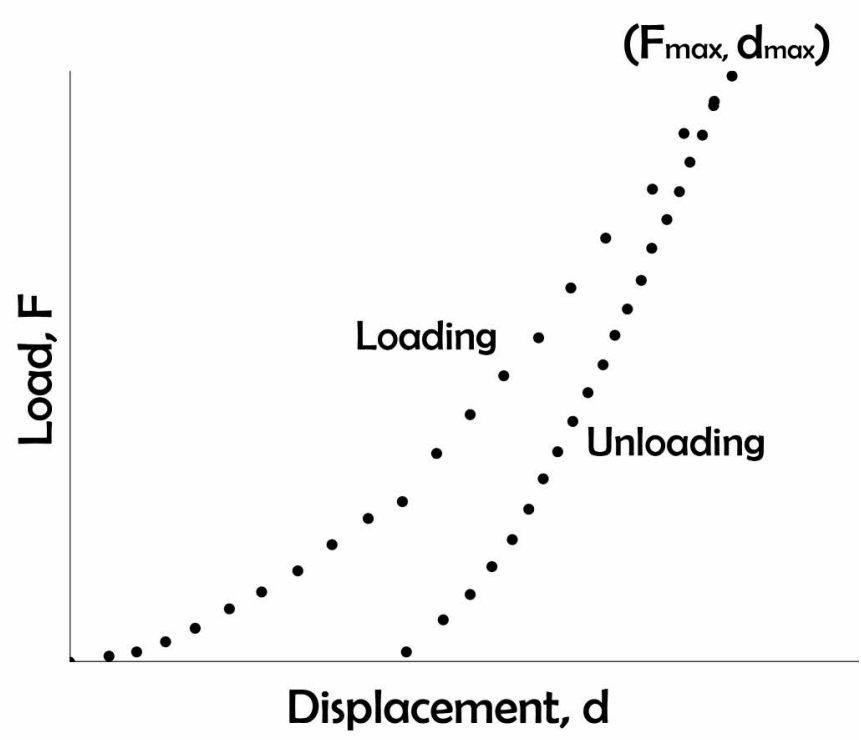

Figure 4.5. A typical load-displacement curve obtained during nanoindentation.

The sample was baked into a cylinder of bakelite and the sample was tilted so that polishing would give a tapered cross-section and before measurement the surface was cleaned with acetone and mounted in the instrument. The points for nanoindentation were selected carefully with the help of an optical microscope.

\footnotetext{
${ }^{1}$ Not to be intermixed with enthalpy in Section 2.1
} 
Macro-particles from to the deposition process could be avoided for selection. In order to minimize the effect of the substrate, the indentation depth was less than $10 \%$ of the film thickness. For statistical purposes, 40 points were selected for each sample. 


\section{CHAPTER 5}

\section{Theoretical Modeling}

\subsection{Density Functional Theory}

\subsubsection{Theoretical Background}

A material system can be seen as a very large number of atomic nuclei that interact with each other and with electrons. In materials science the total energy of a material system is of interest, which in the non-relativistic case is obtained if the Schrödinger equation is solved [76]. The Schrödinger equation, that was first published 1926 [77] by the Austrian Physicist Erwin Schrödinger, initiated a paradigm shift in physics. For this equation a wave-function of the material system is needed and a specific Hamiltonian needs to be expressed. Erwin Schrödinger is buried in Alpbach of Tyrolia and on his headstone the Schrödinger equation is expressed as can be seen in Figure 5.1. As the number of nuclei and electrons are large the problem of exactly solving the Schrödinger equation of a material system becomes too complex. Instead of solving the Schrödinger equation exactly with a many-body wave function [78] of the system density functional theory (DFT) can be used [79]. The starting point in DFT is still the Hamiltonian and if no external potential is present this is written as:

$\hat{H}=-\frac{\hbar^{2}}{2 m_{e}} \sum_{i} \nabla_{i}^{2}-\frac{\hbar^{2}}{2 M_{I}} \sum_{I} \nabla_{I}^{2}+\frac{1}{2} \sum_{i \neq j} \frac{e^{2}}{\left|\bar{r}_{i}-\bar{r}_{j}\right|}+\frac{1}{2} \sum_{I \neq J} \frac{e^{2} Z_{I} Z_{J}}{\left|\bar{R}_{I}-\bar{R}_{J}\right|}-\sum_{i, I} \frac{e^{2} Z_{I}}{\left|\bar{r}_{i}-\bar{R}_{I}\right|}$

$M$ is the mass of each ion, $m_{e}$ is the mass of an electron, $\hbar$ is the reduced Planck constant, $\bar{r}$ and $\bar{R}$ are the positions of the electrons and ions, $e$ is the elementary charge and $Z$ is the atomic number of each ion. In the expression the first term is the total kinetic energy operator of all the electrons and the second term is the 


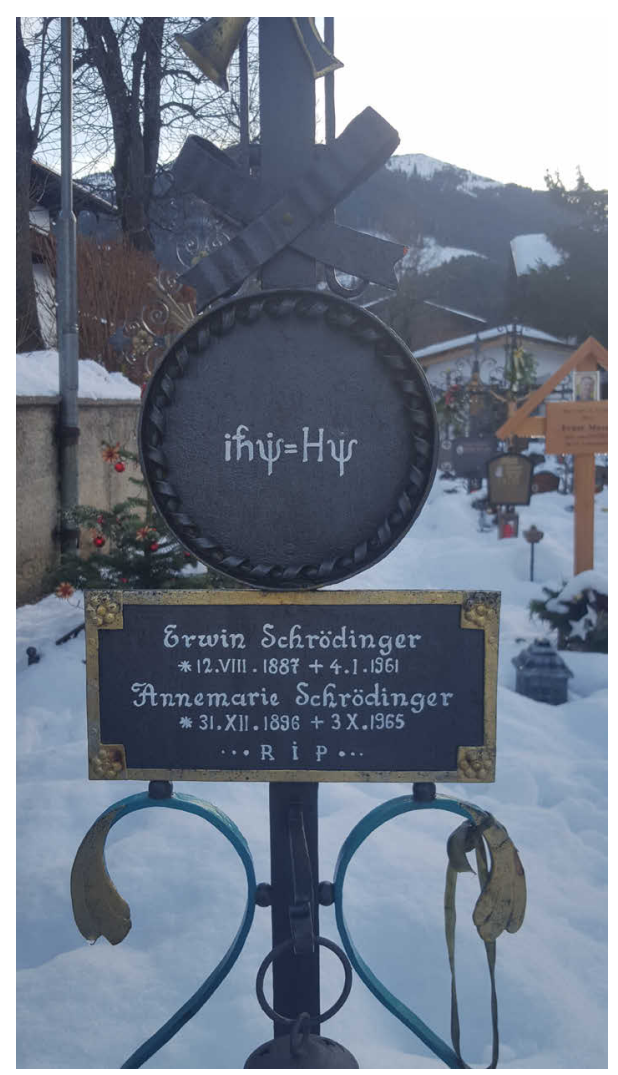

Figure 5.1. A photograph by the author taken in January 2018 of Erwin Schrödinger's headstone in Alpbach of Tyrolia in Austria. In the photograph the Schrödinger equation is expressed.

the total kinetic energy operator of all the positively charged nuclei. The third term is the potential energy due the electrical interaction between the electrons and the fourth term is the potential energy due the electrical interaction between the nuclei. Finally, there is a fifth term that is the potential energy due to the electron interaction with each nuclei.

DFT is based on the Born-Oppenheimer approximation [80, 81] that uses the fact that an electron has a relatively small mass compared to the nuclei. This implies that the wave-function can be considered as a product of one electronic part and one nuclei part, respectively. The nuclei part is fixed when solving the electronic part and furthermore the nuclei part can be solved classically. The following discussion is about how to solve the electronic subproblem. When the electronic part is considered the electronic interaction with all the nuclei is treated as if an external potential, $V_{e x t}$, is acting on them. The Hamiltonian that is needed 
for the electronic subproblem is expressed as [79]

$$
\hat{H}=-\frac{\hbar^{2}}{2 m_{e}} \sum_{i} \nabla_{i}^{2}+\frac{1}{2} \sum_{i \neq j} \frac{e^{2}}{\left|\bar{r}_{i}-\bar{r}_{j}\right|}+\sum_{i} V_{e x t}\left(\bar{r}_{i}\right)
$$

Instead of constructing a wave function representing all the electrons DFT uses the total electron density to calculate the energy. What is here referred as the electron density is for a single electron the probability distribution in space. One advantage of using the electron density instead of using a many-body wave function is that the electron density is a function of three spatial coordinates while the many-body wave function is a function of the number of electrons times three.

\subsubsection{The Hohenberg-Kohn Theorems}

DFT relies on two theorems by Hohenberg and Kohn [79]. The first theorem states that for a system of interacting electrons in an external potential, the potential is uniquely determined by the ground state electron density, $n_{0}(\bar{r})$, up to an additive constant. The second theorem states that the energy of the system for any given external potential can be expressed as a functional of the electron density, $n(\bar{r})$ [82]. A functional is in general a scalar function of a vector-valued function, but in this context the energy functional is a function of a scalar function of three spatial variables. The energy functional, $E$, according to this theorem is expressed

$$
E[n(\bar{r})]=T[n(\bar{r})]+E_{\text {int }}[n(\bar{r})]+\int d^{3} r V_{\text {ext }}(\bar{r}) n(\bar{r})
$$

$T$ denotes the total kinetic energy of the electrons, $E_{\text {int }}$ is the energy due to interaction between the electrons and the last term is the energy contribution due the interaction between the electrons and the external potential. If the ground state density is known, the first theorem implies that the external potential can be determined and if this is known all the properties of the system can be calculated. The ground state density, $n_{0}(\bar{r})$, is the density that minimizes the energy functional. Subsequently, if $E[n(\bar{r})]$ would be known, then all electronic structure problems can be solved. Additionally, it should be noted that the external potential is determined by the ground state density, but at the same time it follows from Equation 5.2 that the ground state density depends on the external potential.

\subsubsection{The Kohn-Sham Equations}

In order to obtain the ground state density and the ground state energy Kohn and Sham proposed that the system with interacting electrons should be replaced with a system of non-interacting electrons. The key assumption is that both systems should have their energies minimized by the same ground state density $[81,83]$. The advantage of this assumption is that a single density and energy can be calculated independently for each electron. So, the method is to find the 
electron density that minimizes the energy of the non-interacting system and when that is done, the energy of the real system is calculated. The energy functional of the real system in Equation 5.3 is rewritten and is denoted $E_{K S}$ according to

$$
E_{K S}[n(\bar{r})]=T[n(\bar{r})]+E_{\text {Hartree }}[n(\bar{r})]+E_{x c}[n(\bar{r})]+\int d^{3} r V_{\text {ext }}(\bar{r}) n(\bar{r})
$$

The interaction between the electrons have been divided into two parts, where $E_{\text {Hartree }}$ is the energy as a result of classical Coulumb interaction while $E_{x c}$ is the exchange-correlation energy. For the non-interacting system a potential acting on a single electron is needed and this is denoted effective potential, $V_{\text {eff }}$. With this potential the energy functional, $E_{s}$, of the non-interacting system is expressed

$$
E_{s}[n(\bar{r})]=T_{s}[n(\bar{r})]+\int d^{3} r V_{e f f}(\bar{r}) n(\bar{r})
$$

It can be shown that the Equation 5.4 and 5.5 are minimized if the choice of the effective potential is

$$
V_{e f f}(\bar{r})=V_{e x t}+\int \frac{n\left(\bar{r}^{\prime}\right)}{\left|\bar{r}-\bar{r}^{\prime}\right|} d \bar{r}^{\prime}+\frac{\delta E_{x c}[n(\bar{r})]}{\delta n(\bar{r})}
$$

With this choice of effective potential one Schrödinger-like equation of each electron can be solved and because the wave function of each electron is time-independent it can be formulated as an eigenvalue problem, where each wave function is an electron orbital $\psi_{i}$ with a corresponding eigenenergy, $\epsilon_{i}$. The equations are referred as the Kohn-Sham equations and for each electron or orbital the equation is expressed [83]:

$$
\left(-\frac{\hbar^{2}}{2 m_{e}} \sum \nabla^{2}+v_{e f f}(\bar{r})\right) \psi_{i}(\bar{r})=\epsilon_{i} \psi_{i}(\bar{r})
$$

The electron density of the system is the sum over all occupied states and can thus be written [79]:

$$
n(\bar{r})=\sum_{i}^{N}\left|\psi_{i}(\bar{r})\right|^{2}
$$

The approach of Kohn and Sham is first to make a guess of the electron density and with that construct the effective potential. Then Equation 5.7 for each electron is solved followed by a calculation of the total electron density. If this calculation gives the same density as the guessed, then it can be concluded that this is the density that minimizes the energy functional of both systems. If the latter density does not match the guessed, the procedure is repeated with this new density as guessed until they match. When they match, the energy in Equation 5.4 can be calculated for the real system.

Finally, to calculate the total energy the energy of the nuclei-nuclei interaction, $E_{I I}$, as mentioned usually calculated, is added. An expression of the total energy is given by

$$
E_{t o t}[n(\bar{r})]=T[n(\bar{r})]+E_{\text {Hartree }}[n(\bar{r})]+E_{x c}[n(\bar{r})]+\int d^{3} r V_{\text {ext }}(\bar{r}) n(\bar{r})+E_{I I}
$$




\subsubsection{Exchange-correlation Effects}

The effective potential in Equation 5.6 depends on the exchange-correlation energy, but the functional, $E_{x c}$ cannot be calculated exactly and thus it needs to be approximated. There are many methods of doing this and here two common methods are mentioned.

The local density approximation (LDA) [83] calculates the exchange-correlation energy of a homogeneous electron gas with the same electron density as the system that is approximated and it assumes that this energy is the same as for the system. With this purpose the exchange-correlation energy of a single electron, $\epsilon_{x c}$, in the homogeneous gas depending on the density is calculated and the exchangecorrelation energy is then expressed

$$
E_{x c}[n(\bar{r})]=\int d^{3} r \epsilon_{x c}[n(\bar{r})] n(\bar{r})
$$

Another method to approximate the exchange-correlation energy is the generalized gradient approximation (GGA) [84] and in this method $\epsilon_{x c}$ is not only a functional of the electron density, but also of the absolute value of the gradient of the electron density of each point.

There are different variations of GGA and for this thesis the method developed by Perdew, Burke and Ernzerhof is used (PBE) [84]. The method is non-empirical. It has been proven to be fast and give accurate lattice parameters for MAX phases and it is therefore an appropriate choice for this work.

\subsubsection{Plane Waves}

Each Kohn-Sham equation, i.e., Equation 5.7 is solved numerically and in order to do that each orbital is represented as an expansion of linearly independent plane waves. In order to construct that representation the Bloch theorem [85] is applied, which is valid when a crystal structure is periodic and thus has a periodic potential:

$$
\psi_{i, \bar{k}}(\bar{r})=e^{i \bar{k} \cdot \bar{r}} u_{i, \bar{k}}(\bar{r})
$$

The function $u_{i, \bar{k}}(\bar{r})$ is also periodic, which implies that it can be Fourier expanded, where the periodicity is the same as the the periodicity of the potential and the underlying structure. The $\bar{k}$-vectors are the reciprocal lattice vectors, where each vector is denoted $\bar{G}$ and the Fourier expansion is then:

$$
u_{i, \bar{k}}(\bar{r})=\sum_{\bar{G}} c_{i, \bar{k}, \bar{G}} e^{i \bar{G} \cdot \bar{r}}
$$

If the expression in Equation 5.11 and the expansion in Equation 5.12 are plugged in to Equation 5.8, an expression for the electron density is obtained:

$$
n(\bar{r})=\sum_{i} \int_{B Z}\left|\psi_{i, \bar{k}}(\bar{r})\right|^{2} d^{3} k
$$


The sum is over all occupied bands and the integral is taken over the first Brillouin zone of the reciprocal lattice, but in reality the integral is usually replaced by a sum over a finite number of k-points [86].

\subsubsection{Pseudopotentials and Projector Augmented Waves}

The valence electrons of the atoms of a lattice are affected by potentials originating from the nuclei as well as from the core electrons. Because changes in the chemical environment do not affect the core states to a greater extent, the potential that the valence electrons experience from the core electrons can be regarded as fixed, which in turn implies that the potential of the nuclei and the core electrons can be combined to an effective potential that in this context is referred as a psudeopotential. The pseudopotential is weaker in the core regions than the real acting potential, but outside a cutoff radius the two different potentials are identical. The corresponding wave functions of the valence electrons are referred as pseudo wave functions, which are smooth in the core regions instead of rapidly oscillating [87].

For the calculations of this work the projector augmented wave method (PAW) $[88,89]$ has been used. It is a way of avoding the problem of rapidly oscillating wave functions in the core regions by using smooth auxiliary wave functions. The auxiliary wave functions are not normconserving, but through a transformation they still contain all information of the all-electron wave functions.

\subsection{Mean Field Approximation}

In order to calculate the entropy, $S^{1}$, in Equation 2.1 the mean field approximation was used. In this context only configurational entropy is considered, which means no vibrational contributions. This is valid, when the difference in lattice parameter is small. The configuration entropy depends on the number of the configurations of the atoms in the lattice. For the calculations in Paper II the mean field approximation was used and this states that the number of configurations depend on the average composition of the alloy containing elements. The mole fractions of each element are denoted $x, y$, and $z$ and the Boltzmann constant, $k_{\mathrm{B}}$ and is expressed [90]:

$$
S=k_{B}(x \ln x+y \ln y+z \ln z)
$$

\footnotetext{
${ }^{1}$ Not to be intermixed with the Seebeck coefficient in Section 2.6
} 


\section{CHAPTER 6}

\section{Material Systems}

\subsection{TiAlN}

During the 1980's TiN was the most used nitride hard coating for wear resistance until TiAlN was introduced later in the same decade [91]. Cutting inserts coated with TiN improved cutting performance [92], but adding Al led to better wear resistance and oxidation resistance [38]. One of the reasons to improved wear resistance was the age hardening effect, that later was observed and explained [93]. The improved oxidation resistance was due to an $\mathrm{Al}_{2} \mathrm{O}_{3}$ layer formed at elevated temperatures and this layer acts as a protection against oxygen diffusion into the film [94].

The miscibility of AIN and TiN is not high, but with PVD it is possible to form metastable TiAlN solid solutions with fcc structure in the miscibility gap [95-97]. The two different compositions of $\mathrm{Ti}_{\mathrm{x}-1} \mathrm{Al}_{\mathrm{x}} \mathrm{N}$ in this thesis was of a metastable fcc structure. Because the solution is thermodynamically metastable, an elevation of temperature leads to spinodal decomposition, i.e., to a state with a lower free energy with the products $c$-TiN and $c$-AlN, see step one in Equation 6.1. However, the total free energy can be even more lowered by the phase transformation of $c$ AlN into its stable $h$-AlN phase, see step 2 in Equation 6.1. [98-100] This second transformation occurs by nucleation and growth [42]. Step 1 in the decomposition has been shown to start at around $800{ }^{\circ} \mathrm{C}$ during isothermal annealing for 2 hours [98]. Age hardening is an effect of the spinodal decomposition and a drop of hardness is associated with the second phase transformation [93].

$$
c-T i A l N \underset{1}{\Rightarrow} c-T i N+c-A l N \underset{2}{\Rightarrow} c-T i N+h-A l N
$$

A recent trend is to study how the thermodynamic stability and the spinodal decomposition are affected by vacancies in TiAlN [101-103]. The contribution 
from this thesis is however on HPHT behavior of TiAlN. In this context, it has been shown theoretically that a pressure of $4 \mathrm{GPa}$ at $0 \mathrm{~K}$ increases the solubility of $\mathrm{Al}$ in $\mathrm{Ti}_{\mathrm{x}-1} \mathrm{Al}_{\mathrm{x}} \mathrm{N}$ and thus increases the stability of the system [104]. Earlier, it was also theoretically shown that the mixing enthalpy increases as a consequence of applied pressure, which promotes spinodal decomposition. The mixing enthalpy was calculated for 0, 10, 15 and $20 \mathrm{GPa}$ [105]. Furthermore, calculations have shown that the $c$-AlN phase is stabilized by increased pressure or increasing temperature and pressure [90, 106].

It was later observed in accordance with calculations that a pressure of $2 \mathrm{GPa}$ and a temperature of $900{ }^{\circ} \mathrm{C}$ promote spinodal decomposition. This was concluded by comparing an annealed deposited cutting insert at ambient pressure with one used in a cutting test [106]. The stabilization of $c$-AlN has also been observed. This was done with a powder sample of TiAlN and under different temperature and pressure conditions. The temperatures were in the range 900 to $1700{ }^{\circ} \mathrm{C}$ and the pressure 8 to $14 \mathrm{GPa}$ [106]. In Paper I, the contribution from this work to the studies about HPHT behavior of TiAlN is presented.

\subsection{TiZrAlN}

ZrN has high hardness [107] and good oxidation resistance [108]. When Ti was added, it was shown that the driving force for phase separation in $c$-TiZrN is low. Even after annealing at $1200{ }^{\circ} \mathrm{C}$ for 2 hours, the system remains in its multicomponent cubic phase. As a consequence, the hardness remains high also after annealing above $1000{ }^{\circ} \mathrm{C}$ [109].

Another studied system is where $\mathrm{Al}$ instead of $\mathrm{Ti}$ is added, i.e., ZrAlN, for which it has been shown that the miscibility gap is large [94]. Because of the lattice mismatch between $\mathrm{Al}$ and $\mathrm{Zr}$ spinodal decomposition does not occur and instead $h$-AlN is formed by nucleation and growth, while the cubic lattice approaches $c$-ZrN [110]. For $c$-ZrAlN age hardening has been observed [111].

After the first synthesis and experimental characterization of TiAlZrN and ab initio calculations on the system [112], a theoretical study on thermodynamic stability showed that the system is not thermodynamically stable at $0 \mathrm{~K}$ and that it does tend to decompose through spinodal decomposition [113]. For sputtered films, it was after shown that stoichiometric films with low $\mathrm{Al}$ content exhibit the best thermal stability [114]. In Paper II, the first contribution from this work to the study of TiZrAlN is presented, which is about the high temperature phase decomposition of TiZrAlN. The Gibbs free energy a $0 \mathrm{~K}$ is shown in Figure 6.1. It is noted that a mixture with low $\mathrm{Ti}$ content and a $\mathrm{Zr}$ :Ti ratio of 1:1 is not stable. By increasing the Ti content, the composition becomes less unstable. The TiZrN mixture has a very low tendency for decomposition. It seems that $c$-AlN is the most stable phase, but the calculations do not take the hexagonal phase into account and the transformation into $h$-AlN is expected. The calculations show that $\mathrm{Al}$ does not tend to be mixed with $\mathrm{Ti}$ and especially not $\mathrm{Zr}$.

Extended studies on the material system have been performed. Based on experimental data and first-principles calculations, phase diagrams for the temperatures 

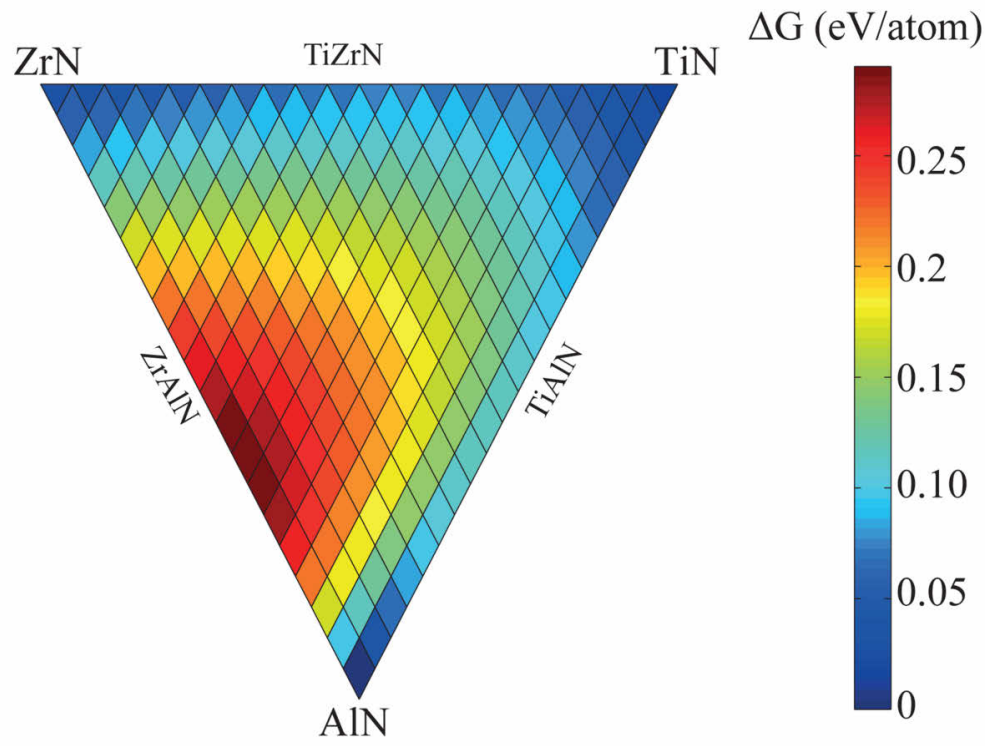

Figure 6.1. The calculated mixing enthalpy i.e. Gibb's free energy at $0 \mathrm{~K}$ of $c$-TiZrAlN. Image courtesy of Hans Lind.

$850-1500{ }^{\circ} \mathrm{C}$ have been constructed. In all cases there are regions, where TiZrAlN spinodally decomposes into triple binaries. [115] Furthermore, thermal expansion coefficients depending on temperature have been calculated. Thermal stability of thin films grown by reactive magnetron sputtering have been studied $[116,117]$. Paper III is an in-depth study of the different decomposition routes and strain evolution in TiZrAlN.

\subsection{Tungsten Carbide}

Tungsten carbide is a kind of cemented carbide produced by sintering of powder of the composites together with a binder material [118]. In Paper II and III, WC-Co is used as substrate of the deposited films, where Co acts as the binder metal. Tungsten carbide is widely used for machining of for instance carbon steel and stainless steel $[119,120]$. The used substrates were commercial cutting inserts with hexagonal WC phase and cubic Co phase. The advantages of tungsten carbide are its high hardness and good wear resistance [118]. In comparison with diamond and $\mathrm{PCBN}$ it is cheaper to produce. 


\subsection{PCBN}

PCBN inserts mainly consisting of $c-\mathrm{BN}$ are used for machining of hardened steel because it has advantages compared with cemented carbide and diamond. It is harder than cemented carbide and though it is softer than diamond it has the advantage of not being reactive with iron based alloys. The $c$-BN is the hardest material known next to diamond and has hardness around $50 \mathrm{GPa}$ while diamond has around $90 \mathrm{GPa}$. Other benefits are high thermal conductivity and low chemical reactivity [121]. The use of $\mathrm{PCBN}$ in hard machining is increasing due to its performance [122].

At room temperature the hexagonal phase of $\mathrm{BN}$ is stable and $c$-BN is synthesized by a HPHT process [123]. During HPHT conditions it is stable and therefore the tendency for revert phase transformation during machining is very low. In order to produce the PCBN another HPHT process is used i.e. sintering of $c$-BN powder and the other components of the composite. The used PCBN substrate in Paper I consists of $c$-BN $90 \%$ and the rest is the binding material consisting of stable $h$-AlN, $\mathrm{AlB}_{2}$ and traces of $\mathrm{AlB}_{12}$. The composite is commercial, but for this work specially designed substrates instead of inserts were used.

\subsection{MAX phases}

MAX phases are a class of ternary carbides and nitrides. In general they are denoted $\mathrm{M}_{\mathrm{n}+1} \mathrm{AX}_{\mathrm{n}}$, where $\mathrm{M}$ is a transition metal from group $3(\mathrm{Sc}, \mathrm{Lu}), 4(\mathrm{Ti}, \mathrm{Zr}$, $\mathrm{Hf}), 5(\mathrm{~V}, \mathrm{Nb}, \mathrm{Ta}), 6(\mathrm{Cr}, \mathrm{Mo})$ or $7(\mathrm{Mn})$. A is an element from the groups $12(\mathrm{Cd})$, 13 (Al, Ga, In, Tl), 14 (Si, Ge, Sn, Pb), 15 (P, As) or $16(\mathrm{~S})$. X denotes either $\mathrm{C}$ or $\mathrm{N}$ and furthermore $n=1,2$ or 3 [124]. The interest of MAX phases from a material scientific point of view is because of their unique combination of metallic and ceramic properties. They possess high electrical and thermal conductivity like metals, but are also resistant to oxidation and thermal shock like ceramics. These properties are partly explained by the layered structure of the MAX-phases. Furthermore the M-X bonds are stronger than the M-A bonds [125, 126].

Table 6.1. Structural parameters of $\mathrm{Ti}_{2} \mathrm{AlC}[126]$.

\begin{tabular}{ccccc}
\hline \hline Element & $\mathrm{x}$ & $\mathrm{y}$ & $\mathrm{z}$ & Wyckoff position \\
\hline $\mathrm{Ti}$ & $1 / 3$ & $2 / 3$ & 0.084 & $4 \mathrm{f}$ \\
$\mathrm{Al}$ & $1 / 3$ & $2 / 3$ & $3 / 4$ & $2 \mathrm{~d}$ \\
$\mathrm{C}$ & 0 & 0 & 0 & $2 \mathrm{a}$ \\
\hline
\end{tabular}

The most common MAX phases are $\mathrm{M}_{2} \mathrm{AX}$-phases $(n=1)$. This stoichiometry is referred as 211. These phases consist of $\mathrm{M}_{6} \mathrm{X}$ octrahedra with $\mathrm{X}$ in the center interleaved with layers of A. Neighboring octahedra share their edges. The MX layers are twinned with respect to each other where the A-layers act as mirror planes. Because of the twinning, the unit cell has to include three MX layers and two A-layers and it is hexagonal, where the A-elements are hexagonal in plane. 
The $\mathrm{M}_{6} \mathrm{X}$ octrahedral building block is the same as for the binary MX [126]. The lattice a-parameter is around $3 \AA$ and the c-parameter is around $13 \AA$. The space group of the unit cell is $\mathrm{P} 63 / \mathrm{mmc}$. $\mathrm{Ti}_{2} \mathrm{AlC}$ serves here as archetypical 211 MAX phase. In Table 6.1, structrual data of this phase are shown. It shows the coordinates of each element in the unit cell together with their Wyckoff positions.

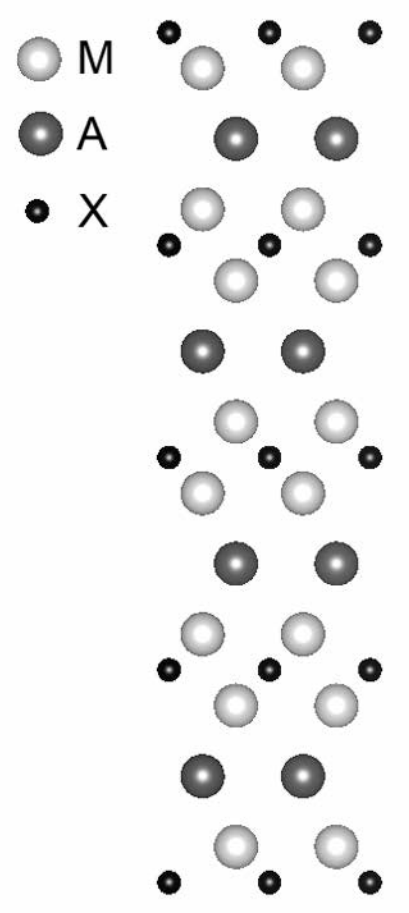

Figure 6.2. The $\mathrm{M}_{2} \mathrm{AX}$ structure viewed along the [110] zone axis.

\section{6 $\mathrm{ScTaN}_{2}, \mathrm{ScNbN}_{2}$ and $\mathrm{ScVN}_{2}$}

$\mathrm{ScTaN}_{2}$ is not a MAX-phase, but it shares some similar structural properties with the 211 MAX phase in the sense that the unit cell is hexagonal, the structure is layered and the space group is $\mathrm{P} 63 / \mathrm{mmc}$. The building blocks of the structure consist of $\mathrm{TaN}_{3}$ prisms and $\mathrm{ScN}_{3}$ octrahedra. One way of viewing the layered structure is to view the layers as layers of the building blocks, where the building blocks are repeating themselves. In each layer of $\mathrm{TaN}_{3}$ prisms the prisms are edgesharing. The $\mathrm{ScN}_{3}$ octrahedra building blocks are also edge-sharing. Figure 6.3 shows the hexagonal structure, where balls represent the Sc atoms, Ta atoms and N 
atoms, respectively. It can be seen that in the center of each projected octrahedra, there is one Sc atom and that in the center of each projected prism there is one Ta atom. Furthermore, it can be seen that two layers of the same building block are twisted with respect to each other as in the case of the $\mathrm{M}_{6} \mathrm{X}$ octrahedral building block of a MAX phase. It can also be seen that $\mathrm{N}$ is shared between $\mathrm{TaN}_{3}$ prisms and $\mathrm{ScN}_{3}$ octrahedra. The structure in Figure 6.3 has approximately the a-lattice parameter $3 \AA$ and the c-lattice parameter $11 \AA$ [127].

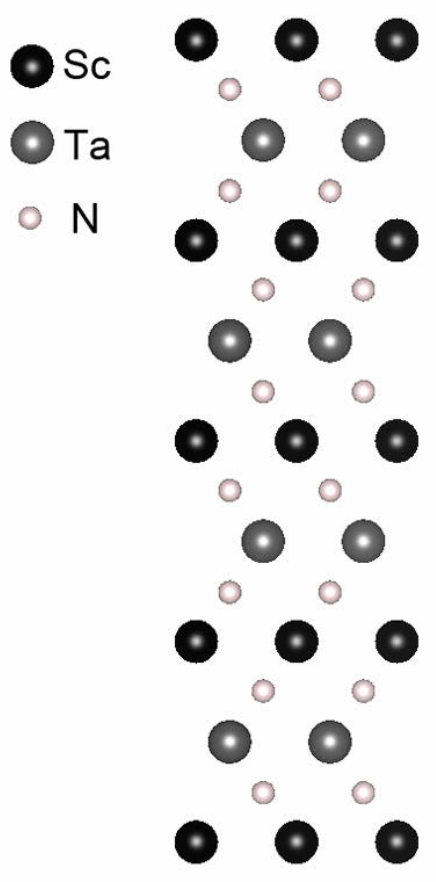

Figure 6.3. The $\mathrm{ScTaN}_{2}$ structure viewed along the [110] zone axis.

Table 6.2 presents structural data of this phase. It shows the coordinates of each element in the unit cell together with their Wyckoff positions. The data can be compared with the data in table 6.1 and it can be seen that the atomic coordinates are inverted. Thus, the $\mathrm{ScTaN}_{2}$-type structure can be refeered as an inverse MAX phase. This is a term that never has been used before for this kind of structure. The inverted relationship between the two phases can also be seen if Figure 6.2 and 6.3 are compared. Sc in the inverted MAX phase is positioned where the element $\mathrm{X}$ is positioned in the lattice in Figure 6.2 and $\mathrm{N}$ is positioned where element $\mathrm{M}$ is positioned in the same lattice.

So far, only two experimental studies $[127,128]$ and calculations $[127,129]$ have been performed. This motivates the study in this work on inverse MAX phases. It has been shown that this phase can be synthesized through high temperature treat- 
Table 6.2. Structural parameters of $\mathrm{ScTaN}_{2}$ [127].

\begin{tabular}{ccccc}
\hline \hline Element & $\mathrm{x}$ & $\mathrm{y}$ & $\mathrm{z}$ & Wyckoff position \\
\hline $\mathrm{Sc}$ & 0 & 0 & 0 & $2 \mathrm{a}$ \\
$\mathrm{Ta}$ & $1 / 3$ & $2 / 3$ & $3 / 4$ & $2 \mathrm{~d}$ \\
$\mathrm{~N}$ & $1 / 3$ & $2 / 3$ & 0.1231 & $4 \mathrm{f}$ \\
\hline
\end{tabular}

ment of mixed fine powder of $\mathrm{ScN}$ and $\mathrm{TaN}$ or $\mathrm{Ta}_{3} \mathrm{~N}_{5}$, respectively [127]. Also, the crystallographic structure has been experimentally verified and some material properties have been measured $[127,128]$. $\mathrm{ScTaN}_{2}$ is a diamagnetic narrowbandgap semiconductor or semimetal [127]. Finally, calculations have shown that the phase is thermodynamically stable, when compared to cubic $\mathrm{ScN}$ and cubic TaN and also compared to the corresponding cubic TaN phase.[129]. Paper IV-VI contain the contribution from this work to the study on this material system.

$\mathrm{ScNbN}_{2}$ is also also an inverse MAX phase and its structural data are shown in Table 6.3. Consequently, the structure consists of $\mathrm{NbN}_{3}$ prisms and $\mathrm{ScN}_{3}$ octahedra with an a lattice paramater around $3 \AA$ together with a c lattice parameter around $11 \AA$ [130]. The phase has the same structure as the one in Figure 6.3, but with the the exception that $\mathrm{Sc}$ should be replaced with $\mathrm{Nb}$.

Table 6.3. Structural parameters of $\mathrm{ScNbN}_{2}[130]$.

\begin{tabular}{ccccc}
\hline \hline Element & $\mathrm{x}$ & $\mathrm{y}$ & $\mathrm{z}$ & Wyckoff position \\
\hline $\mathrm{Sc}$ & 0 & 0 & 0 & $2 \mathrm{a}$ \\
$\mathrm{Nb}$ & $1 / 3$ & $2 / 3$ & $3 / 4$ & $2 \mathrm{~d}$ \\
$\mathrm{~N}$ & $1 / 3$ & $2 / 3$ & $1 / 8$ & $4 \mathrm{f}$ \\
\hline
\end{tabular}

$\mathrm{ScNbN}_{2}$ is expected to have similar properties to $\mathrm{ScTaN}_{2}$, due the fact that Ta and $\mathrm{Nb}$ behave in a similar way. Up to this date only one experimental study has been performed and it has been shown that this phase can be synthesized from powder compacts of $\mathrm{ScN}$ and $\mathrm{Nb}$ at high temperature under nitrogen pressure as well as by nitridation of Sc-Nb alloys prepared by arc-melting in nitrogen atmosphere. In this study the nitrogen occupancy was $50 \%$ and the crystallographic structure was experimentally verified [130]. Similar to $\mathrm{ScTaN}_{2}$ the $\mathrm{ScNbN}_{2}$ phase is predicted to be thermodynamically stable [129]. Paper IV-VI contain the contribution from this work to the study on this material system.

$\mathrm{ScVN}_{2}$ is expected to be an inverse MAX phase, but in contrast to the two other mentioned inverse MAX phases, this phase has never been synthesized and thus no structural parameters are given here. However, from a thermodynamical point of view this phase is based on calculations expected to be thermodynamically stable and subsequently is expected to exist. [129]. This motivates why this phase ought to be studied in this work, which is presented in Paper IV-VI. 


\section{CHAPTER 7}

\section{Summary and Contribution to the Field}

The aim of this thesis is to increase the fundamental understanding of nitride coatings and thin films. The contribution from this thesis is first to the study of TiAlN and TiAlN-based coatings and second to the study of inverse MAX phases. This chapter is a summary of the papers included in this thesis and a discussion on how the papers may contribute to the research field.

\subsection{TiAlN and TiAlN-based Coatings}

The preceding studies on high temperature and the HPHT behavior of TiAlN are described in Section 6.1. Paper I continues the HPHT studies on TiAlN and PCBN is used as substrate. Consequently, the aim was not only to study TiAlN, but also to investigate if there is any chemical interaction between coating and substrate under these conditions. The HPHT conditions were created and maintained with a Hall belt apparatus. The pressure was set constant to $5.35 \mathrm{GPa}$, duration was either 6 or 66 minutes while the temperature was $1050{ }^{\circ} \mathrm{C}$ or $1300{ }^{\circ} \mathrm{C}$. TiAlN films were also annealed at ambient pressure for comparison. It is shown that the decomposition is slower at higher pressure compared to ambient and that no chemical interaction takes place between TiAlN and PCBN during the HPHT experiments. It is concluded that this film has the potential to protect a PCBN substrate during machining due to a high chemical integrity. Compared to earlier studies it can be noted that the pressure and temperatures are set to other values and that the pressure and temperatures created with the belt apparatus are closer to actual machining conditions. The trend of studying HPHT behavior of TiAlN has in recent years ebbed out, but still the contribution from Paper I is important in verifying theoretical studies and explaining spinodal decomposition in TiAlN under HPHT conditions. 
Another research trend related to TiAlN is alloying with a fourth element with the purpose of tuning the thermodynamic stability. As fourth element Cr, Ta, Y, Hf, B and Nb have been studied [116, 131-134] and Paper II and Paper III are about Zr as fourth element. Paper II is a theoretical and experimental study on the high temperature phase decomposition behavior of TiZrAlN. The calculations on the mixing free energy and the second directional derivatives showed that for $\mathrm{Zr}$-poor compositions the tendency for phase separation between $\mathrm{ZrN}$ and $\mathrm{AlN}$ is strong while the driving force for spinodal decomposition of Zr-rich compositions is low. During spinodal decomposition TiZrN is formed and the calculations predict that this phase is stable at higher temperatures. The experiments took advantage of XRD and STEM to confirm that a low Zr-content thin film after annealing had decomposed in accordance with the calculations while in comparison a high Zr-content film had shown a significantly reduced decomposition rate.

Paper III is an experimental study on phase, microstructure and strain evolution during annealing of TiZrAlN. It uses in situ WAXS and ex situ TEM. It is shown that when the Zr-content decreases and the Al-content increases the decomposition route changes from nucleation and growth to spinodal decomposition. The microstructure is dependent on the composition and in the cases of spinodal decomposition it will consist of cubic domains, where the dislocation-dense structure and nucleation of $h$-AlN result in compressive strain. In the case where spinodal decomposition co-occurs with nucleation and growth of $h$-AlN there is a loss of coherency and a decrease of strain. Paper II and III have contributed to the undestanding of thermodynamic stability and decomposition in TiZrAlN. Especially Paper II have strengthen the motivation of further studying this material system. The studies following Paper II are briefly summarized in the end of Section 6.2.

\subsection{Inverse MAX phases}

The results from the studies on inverse MAX phases before this work are described in Section 6.6. Paper IV-VI are theoretical studies. The emphasis is that these phases in the future should be synthesized and experimentally characterized. Paper IV is a theoretical study on $\mathrm{ScTaN}_{2}, \mathrm{ScNbN}_{2}$ and $\mathrm{ScVN}_{2}$ that based on DFT calculates the enthalpy of formation, elastic properties, density of states (DOS) and thermoelectric properties. It is shown that these nitrides are thermodynamically and elastically stable. Elastic constants and moduli are also presented. The DOS calculations indicate that all three materials systems are narrow-bandgap semiconductors and that quasimetallic behavior can be expected. Their thermoelectric properties are anisotropic and can be tuned by doping. Paper $\mathrm{V}$ is a theoretical study on $\mathrm{ScTaN}_{2}, \mathrm{ScNbN}_{2}$ and $\mathrm{ScVN}_{2}$, that based on DFT calculates the formation enthalpy relative to the competing binary phases, elastic properties and (DOS), when pressure is varied from $0 \mathrm{GPa}$ to $150 \mathrm{GPa}$. It is shown that increased pressure has a stabilizing effect on the thermodynamics. Elastic constants and moduli increase in the range $53-216 \%$ for $\mathrm{ScTaN}_{2}, 72-286 \%$ for $\mathrm{ScNbN}_{2}$, and 61-317 \% for $\mathrm{ScVN}_{2}$ as an effect of pressure increasing from 0 to $150 \mathrm{GPa}$.

While paper IV and V are more general investigations of $\mathrm{ScTaN}_{2}, \mathrm{ScNbN}_{2}$ and 
$\mathrm{ScVN}_{2}$, Paper VI is specifically studying the energy of formation and DOS of these three phases, when one of the $\mathrm{N}$ sites in a supercell is replaced by one vacancy or $\mathrm{C}, \mathrm{O}$ or F. The study is based on DFT calculations. It is shown that asymmetric peak in the DOS close to the Fermi level is the result of having one vacancy in all three phases, which is expected to increase $Z T$. Furthermore, p-doping with one $\mathrm{C}$ dopant in $\mathrm{ScTaN}_{2}, \mathrm{ScNbN}_{2}$ and $\mathrm{ScVN}_{2}$ implies a shift of the Fermi level into the valence band, while n-doping with one $\mathrm{O}$ or $\mathrm{F}$ dopant implies a shift of the Fermi level into the conduction band. The study suggests that the doped phases should be be grown and that especially the figures of merit needs to be evaluated. However, the study implies that these phases doped are interesting candidates for thermoelectrics. 
[1] D. Stout. Phil. Trans. R. Soc. B 366 (2011), 1050.

[2] J.E. Greene. Appl. Phys. Rev. 1 (2014), 041302.

[3] J.E. Greene. J. Vac. Sci. Tech. A 35 (2017), 05C204.

[4] M Mozetič, A. Vesel, G. Primc, C. Eisenmenger-Sittner, J. Bauer, A. Eder, G.H.S. Schmid, D.N. Ruzic, Z. Ahmed, D. Barker, K.O. Douglass, S. Eckel, J.A. Fedchak, J. Hendricks, N. Klimov, J. Ricker, J. Scherschligt, J. Stone, and L. Montelius. Thin Solid Films 30 (2018), 120.

[5] V.S. Pahade, P.C. Chavan, and V.P. Baisane. IJEAS 3 (2016), 75.

[6] Z. Cai, B. Liu, X. Zou, and H.-M. Cheng. Chem. Rev. 118 (2018), 6091.

[7] A. Kafizas, J. Claire, and I.P. Parkin. Coord. Chem. Rev. 257 (2013), 2073.

[8] L. Chen, K.K. Chang, D. Yong, D.R. Jing, and J.W. Ming. Thin Solid Films 519 (2011), 3762.

[9] K. Bobzin. CIRP-JMST 18 (2017), 1.

[10] D. Lundin and K. Sarakinos. Thin Solid Films 27 (2012), 780.

[11] X.-Q. Tan, J.-Y. Liu, J.R. Niu, J.-Y. Liu, and J.-Y. Tian. Materials 11 (2018), 1.

[12] A. Timmins. J. Hist. Philos. 7 (2013), 82.

[13] F. Huber. Eur. J. Philos. 7 (2017), 507.

[14] F. Del Santo. Stud. Hist. Philos. Sci. B 62 (2018), 56.

[15] K.R. Popper. Br. J. Philos. Sci 1 (1950), 117.

[16] W.H. Bragg. Science 60 (1924), 139.

[17] V.I. Levitas. J. Phys.: Condens. Matter. 30 (2018), 163001.

[18] M. Avrami. J. Chem. Phys. 7 (1939), 1103.

[19] J.W. Gibbs. Trans. Conn. Acad. Arts Sci. 3 (1876), 343. 
[20] S. Karthika, T.K. Radhakrishnan, and P. Kalaichelvi. Cryst. Growth Des. 16 (2016), 6663.

[21] C.X. Wang and G.W. Yang. Mat. Sci. Eng. R 49 (2005), 157.

[22] P.H. Mayrhofer, C. Mitterer, L. Hultman, and H. Clemens. Prog. Mater. Sci. 51 (2006), 1032.

[23] L. Hultman. Vacuum 57 (2000), 1.

[24] J.W. Chan. Acta Metall. 10 (1962), 179.

[25] J.W. Chan. Acta Metall. 19 (1971), 795.

[26] J.W. Chan. Acta Metall. 9 (1961), 151.

[27] A.K. da Silva, D. Ponge, Z. Peng, G. Inden, Y. lu, A. Breen, B. Gault, and D. Raabe. Nat. Commun. 9 (2018), 1137.

[28] V. Mohles. Mat. Sci. Eng. A 324 (2002), 190.

[29] M.A. Davies, T. Ueda, R. M'Saoubi, B. Mullany, and A.L. Cooke. CIRP Ann. Manuf. Technol 56 (2007), 581.

[30] R. M'Saoubi, C. Le Calvez, B. Changeux, and J.L. Lebrun. Proc. Inst. Mech. Eng., B J. Eng. Manuf. 216 (2002), 153.

[31] J.S. Koehler. Phys. Rev. B 2 (1970), 547.

[32] V. Mohles. Mater. Sci. Eng. A 319 (2001), 206.

[33] A. Wilm. Metallurgie 223 (1911), 650.

[34] S. Hirsekorn. Texture Microstruct. 12 (1990), 1.

[35] F. Mouhat and F.-X. Coudert. Phys. Rev. B 90 (2014), 224104.

[36] Y. Le Page and P. Saxe. Phys. Rev. B 65 (2002), 104101.

[37] T.J. Seebeck. Ann. Phys. 82 (1826), 133.

[38] P. Eklund, S. Kerdsongpanya, and B. Alling. J. Mat. Chem. C 4 (2016), 3905.

[39] J. Snyder and E.S. Toberer. Nat. Mat. 7 (2008), 104.

[40] N. Kaiser. Appl. Opt. 41 (2002), 3053.

[41] P.B. Barna and M. Adamik. Thin Solid Films 317 (1998), 27.

[42] M.H. Grabow and G.H. Gilmer. Surf. Sci. 194 (1988), 333.

[43] I. Petrov, P.B. Barna, L. Hultman, and J.E. Greene. J. Vac. Sci. Technol. A 21 (2003), 117.

[44] F. Forgerini and R. Marchiori. Biomatter 4 (2014), e28871.

[45] P. Grammatikopoulos, E. Toulkeridou, K. Nordlund, and M. Sowwan. Modelling Simul. Mater. Sci. Eng. 23 (2015), 015008.

[46] B.K. Gan, M.M. Bilek, D.R. McKenzie, and P.D. Swift. Plasma Sources Science T 12 (2003), 508.

[47] A. André. Surf. Coat. Technol. 257 (2014), 308. 
[48] R.L. Boxman and S. Goldsmith. Surf. Coat. Technol. 52 (1992), 39.

[49] A. André. J. Phys. D: Appl. Phys. 40 (2007), 2272.

[50] P.J. Martin, R.P. McKenzie, R.P. Netterfield, P. Swift, S.W. Filipczuk, K.H. Müller, C.G. Pacey, and B. James. Thin Solid Films 153 (1987), 91.

[51] D. Choudhary and J. Bellare. Cer. Int. 26 (2000), 73.

[52] H.T. Hall. Rev. Sci. Instrum. 31 (1960), 125.

[53] C. Venkateswaran, N. Anbukumaran, N.V. Jaya, and S. Natarajan. Rev. Sci. Inst. 68 (1998), 189.

[54] A.M. Glazer. Crystallogr. Rev. 19 (2013), 117.

[55] A.A. Bunaciu, E.g. Udriştioiu, and H.Y. Aboul-Enein. Crit. Rev. Anal. Chem. 45 (2015), 289.

[56] W.H. Bragg. Proc. Royal Soc. A 89 (1913), 246.

[57] A.N. Ivanov and Y.D. Yagodkin. Ind. Lab. 66 (2000), 304.

[58] R. Kužel, J. Černý, V. Valvod, M. Blomberg, and M. Merisalo. Thin Solid Films 247 (1994), 64.

[59] C Giannini, M. Ladisa, D. Altamura, D. Siliqi, and T. Sibillano. Crystals 6 (2016), 87-1.

[60] J. Bolze, V. Kogan, D. Beckers, and M. Fransen. Rev. Sci. Ins. 89 (2018), 085115-1.

[61] J. Li, A. Jiao, S. Chen, W. Zhengzong, and E. Xu. J. Mol. Struct. 1165 (2017), 391.

[62] H. Hahn, W. Brefeld, M. Hesse, J.R. Schneider, H. Schulte-Schrepping, M. Seebach, and M. Werner. J. Synchroton Rad. 5 (1998), 627.

[63] P. Suwanpiniji. Adv. Mat. Sci. Eng. 2016 (2016), 2479345.

[64] N. Schell. Mater. Sci. Forum 772 (2014), 57.

[65] L. Rayleigh. Phil. Mag. 8 (1879), 261.

[66] G. Matteuci, A. Miglori, F. Medina, and R. Castaneda. Eur. J. Phys. 30 (2009), 217.

[67] R.P. Riesz and C.G. Bjorling. Eur. J. Phys. 32 (1961), 889.

[68] F. Wang, H. Zhang, M. Cao, R. Nishi, and A. Takaoka. Micron 41 (2010), 759 .

[69] A.V. Crewe, J. Wall, and L.M. Welter. J. Appl. Phys. 39 (1968), 5861.

[70] C. Sun, E Müller, M. Meffert, and D. Gerthsen. Microsc. Microanal. 24 (2018), 99.

[71] T. Luo and Khursheed. Rev. Sci. Instrum. 77 (2006), 043103.

[72] K. Chung-Soo, A. Sung-Hoon, and J. Dong-Young. Vacuum 86 (2012), 1014.

[73] R.M. Langford and A.K. Petford-Long. J. Vac. Sci. Technol., A 19 (2001), 2186. 
[74] J. Xiao, Y. Huang, Q. Zhou, J. Wang, and X. He. Surf. Eng. (2019), DOI: https://doi.org/10.1080/02670844.2018.1564994.

[75] W.C. Oliver and G.M. Pharr. J. Mater. Res. 7 (1992), 1564.

[76] E. Schrödinger. Phys. Rev. 28 (1926), 1049.

[77] E. Scrödinger. Ann. Phys. 384 (1926), 361.

[78] P.A.M. Dirac. Proc. Royal Soc. A 123 (1929), 714.

[79] R.O. Jones. Rev. Mod. Phys. 87 (2015), 897.

[80] M. Born and R. Oppenheimer. Ann. Phys. 389 (1927), 457.

[81] N. Su and X. Xu. Annu. Rev. Phys. Chem. 68 (2017), 155.

[82] P. Hohenberg and W. Kohn. Phys. Rev. 136 (1964), B864.

[83] W. Kohn and L.J. Sham. Phys. Rev. 140 (1965), A1133.

[84] J.P. Perdew, K. Burke, and M. Ernzerhof. Phys. Rev. Lett. 77 (1996), 3865.

[85] F. Bloch. Z. Phys. 52 (1928), 555.

[86] J.M. Noras. J. Comput. Phys. 36 (1980), 304.

[87] B.J. Austin, V. Heine, and L.J. Sham. Phys. Rev. 127 (1962), 276.

[88] Blöchl. Phys. Rev. B 50 (1994), 17953.

[89] G. Kresse and D. Joubert. Phys. Rev. B 59 (1999), 1758.

[90] B. Alling, A.V. Ruban, A. Karimi, O.E. Peil, S.I. Simak, L. Hultman, and I.A. Abrikosov. Phys. Rev. B 75 (2007), 113510.

[91] H.A. Jehn, S. Hofman, V.E. Rückborn, and W.D. Münz. J. Vac. Sci. Technol. A 4 (1986), 2701.

[92] F.A. Soliman and O.A. Abu-Zeid. Wear 119 (1986), 199.

[93] A. Hörling, L. Hultman, M. Odén, J. Sjölen, and L.J. Karlsson. Surf. Coat. Technol. 191 (2005), 384.

[94] O. Knotek, M. Böhmer, and T. Legendecker. J. Vac. Sci. Technol. A 4 (1986), 2695.

[95] H. Holleck. Surf. Coat. Technol. 36 (1988), 151.

[96] M. Hans, L. Patterer, D. Music, D.M. Holzapfel, S. Evertz, V. Schnabel, B. Stelzer, D. Primetzhofer, B. Völker, B. Widrig, A.O. Eriksson, J. Ramm, M. Arndt, H. Rudigier, and J.M. Schneider. Coatings 9 (2019), 24.

[97] Y. Pinot, M.-H. Tuilier, M.-J. Pac, C. Rousselot, D. Thiaudière, and C. Ulhaq-Bouillet. Thin Solid Films 649 (2018), 160.

[98] A. Hörling, Hultman, M. L. Odén, J. Sjölen, and L.J. Karlsson. J. Vac. Sci. Technol., A 20 (2002), 1815.

[99] N. Norrby, L. Rogström, M.P. Johansson-Jöesaar, N. Schell, and M. Odén. Acta Mater. 73 (2014), 205.

[100] N. Shulumba, O. Hellman, Z. Raza, B. Alling, J. Barriero, F. Mücklich, I.A. Abrikosov, and M. Odén. Phys. Rev. Lett. 117 (2016), 205502. 
[101] K. Grönhagen, J. Ågren, and M. Odén. Scripta Mat. 95 (2015), 42.

[102] M. to Baben, M. Hans, D. Primetzhofer, S. Evertz, H. Reuss, and J.M. Schneider. Mater. Res. Lett. 5 (2017), 158.

[103] K.M. Calamba, I.C. Schramm, M.P. Johansson-Jõesaar, J. Ghanbaja, J.F. Pierson, F. Mücklich, and M. Oden. J. Appl. Phys. 122 (2017), 065301.

[104] D. Holec, F. Rovere, P.H. Mayrhofer, and P.B. Barna. Script. Mat. 62 (2010), 349 .

[105] B. Alling, Odén. M., L. Hultman, and A. Abrikosov. Appl. Phys. Lett. 95 (2009), 181906.

[106] N. Norrby, H. Lind, G. Parakhonskiy, M.P. Johansson, F. Tasnádi, N. Dubrovinsky, N. Dubrovinskaia, I.A. Abrikosov, and Odén. M. J. Appl. Phys. 113 (2013), 053515.

[107] J. Musil, J.J. Musil, M. Kolega, O. Bláhová, J. Vyskočil, and J. Kasl. Mater. Sci. Eng. A 163 (1993), 211.

[108] I. Milošev, B. Strehblow, and B. Navinšek. Thin Solid Films 303 (1997), 246.

[109] A. Hörling, J. Sjölén, H. Willmann, T. Larsson, M. Odén, and L. Hultman. Thin Solid Films 516 (2008), 6421.

[110] L. Rogström, M.P. Johansson, N. Ghafoor, L. Hultman, and M. Odén. J. Vac. Sci. Technol. A 30 (2012), 031504.

[111] L. Rogström, L. Johnson, M.P. Johansson, M. Ahlgren, Hultman. L., and M. Odén. Scr. Mater. 62 (2010), 739.

[112] L. Chen, D. Holec, Y. Du, and P.H. Mayrhofer. Thin Solid Films 519 (2011), 5503.

[113] D. Holec, L. Zhou, R. Rachbauer, and P.H. Mayrhofer. J. Appl. Phys. 113 (2013), 113510.

[114] G. Abadias, V.V. Saladukhin I.A. Uglov, S.V. Zlotski, and D. Eyidi. Surf. Coating. Technol. 237 (2013), 187.

[115] J. Zhou, L. Zhang, L. Chen, Y. Du, and Z.-K. Liu. J. Min. Metall. Sect. B-Metall 53 (2017), 85.

[116] F. Tasnádi, F. Wang, M. Odén, and I.A. Abrikosov. J. Phys.: Condens. Matter 30 (2018), 135901.

[117] G. Abadias, A.Y. Daniliuk, V.V. Solodukhin I.A. Uglov, and S.V. Zlotsky. Inorg. Mater.:Appl. Res. 3 (2018), 148.

[118] H.E. Exner. Int. Met. Rev. 4 (1979), 149.

[119] C.M. Fernandes and A.M. Senos. Int. J. Refract. Met. Hard Mater. 29 (2011), 405.

[120] J. Garcia, V.C. Ciprés, A. Blomqvist, and B. Kaplan. Annu. Rev. Phys. Chem. 68 (2019), 155. 
[121] J. Haines, J.M. Léger, and Bocquillon. Annu. Rev. Mater. Sci. 31 (2001), 1.

[122] J. Díaz-Álvarez, V. Criado, H. Miguélez, and J.L. Cantero. Metals 8 (2018), 852.

[123] O. Fukunaga. Diamond Relat. Mater. 9 (2000), 7.

[124] M.W. Barsoum. Prog. Solid State Chem. 21 (2000), 201.

[125] A. Mockute, P.O.A. Persson, F. Magnus, A.S. Ingeson, S. Olafsson, L. Hultman, and J. Rosén. Phys. Status Solidi RRL 8 (2014), 201.

[126] P. Eklund, M. Beckers, U. Jansson, H. Högberg, and L. Hultman. Thin Solid Films 518 (2010), 1851.

[127] R. Niewa, D.A. Zherebtsov, W. Schnelle, and F.R. Wagner. Inorg. Chem. 43 (2004), 6188.

[128] W. Lengauer and P. Ettmayer. J. Less Common Met. 141 (1988), 157.

[129] S. Kerdsongpanya, B. Alling, and P. Eklund. J. Appl. Phys. 114 (2013), 073512 .

[130] W. Lengauer. J. Solid State Chem. 82 (1989), 186.

[131] H. Lind, R. Forsén, B. Alling, N. Ghafoor, and F. Tasnádi. Appl. Phys. Lett. (2011), 091903.

[132] V Moraes, H. Bolvardi, S. Kolozsvári, H. Riedl, and P.H. Mayrhofer. IJRMHM 71 (2018), 320.

[133] W.M. Seidl, M. Bartosik, S. Kolozsvári, H. Bolvardi, and P.H. Mayrhofer. Surf. Coat. 344 (2018), 244.

[134] R. Rachbauer, S. Massl, E. Stergar, D. Holec, D. Kiener, J. Keckes, J. Patscheider, M. Steifel, H. Leitner, and P.H. Mayrhofer. J. Appl. Phys. 110 (2011), 0235151. 


\section{Papers}

The papers associated with this thesis have been removed for copyright reasons. For more details about these see:

http://urn.kb.se/resolve?urn=urn:nbn:se:liu:diva-155101 


\section{FACULTY OF SCIENCE AND ENGINEERING}

Linköping Studies in Science and Technology, Dissertation No. 1983, 2019 Thin Film Physics Division

Department of Physics, Chemistry and Biology (IFM)

Linköping University

SE-581 83 Linköping, Sweden

www.liu.se
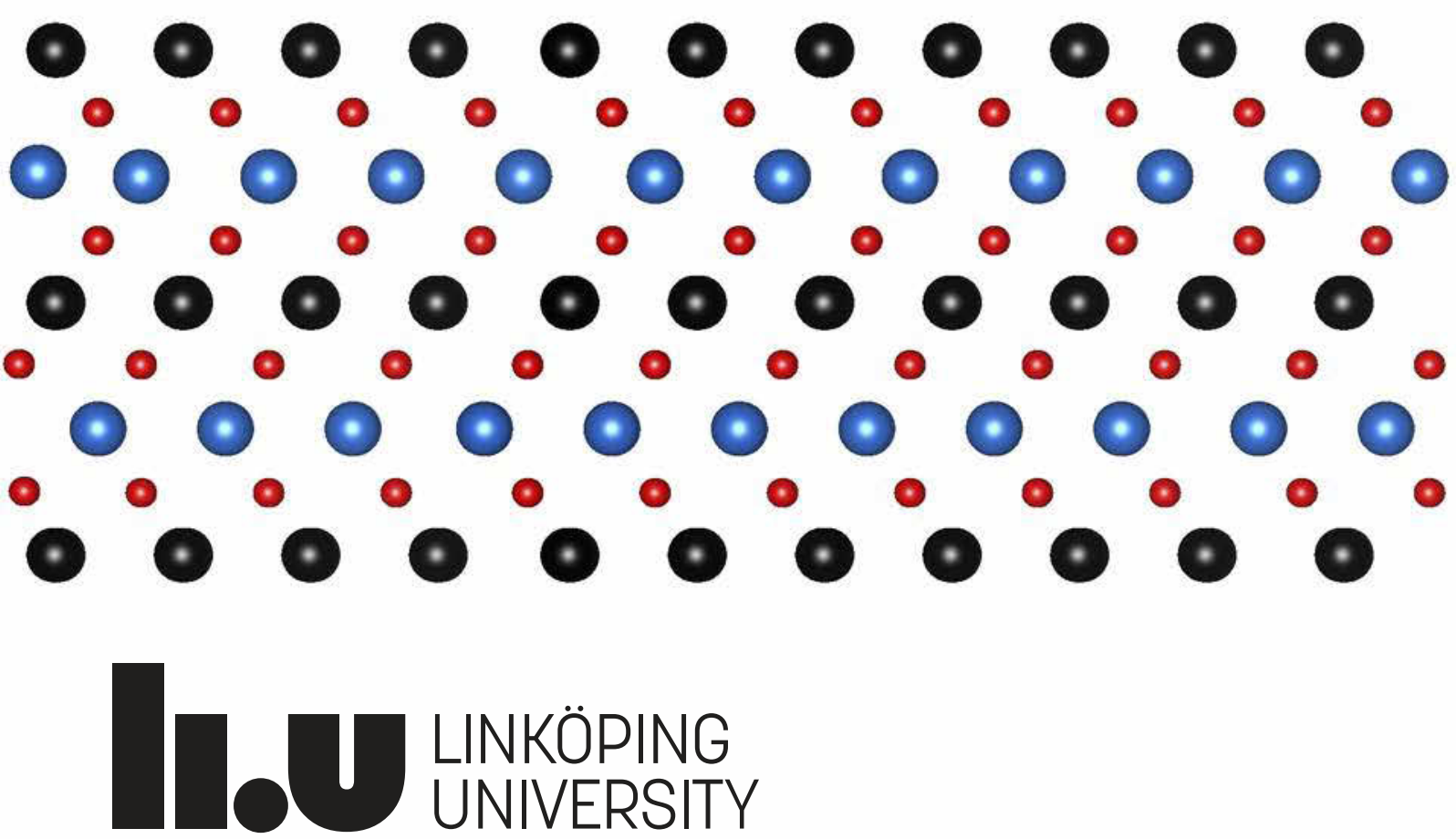